Prepared for the U.S. Department of Energy

under Contract DE-AC05-76RL01830

\title{
Hydrodynamic Modeling Analysis of Union Slough Restoration Project in Snohomish River, Washington
}

Z Yang

T Wang

December 2010

\section{Pacific Northwest}

NATIONAL LABORATORY

Proudly Operated by Battelle Since 1965 


\title{
DISCLAIMER
}

This report was prepared as an account of work sponsored by an agency of the United States Government. Neither the United States Government nor any agency thereof, nor Battelle Memorial Institute, nor any of their employees, makes any warranty, express or implied, or assumes any legal liability or responsibility for the accuracy, completeness, or usefulness of any information, apparatus, product, or process disclosed, or represents that its use would not infringe privately owned rights. Reference herein to any specific commercial product, process, or service by trade name, trademark, manufacturer, or otherwise does not necessarily constitute or imply its endorsement, recommendation, or favoring by the United States Government or any agency thereof, or Battelle Memorial Institute. The views and opinions of authors expressed herein do not necessarily state or reflect those of the United States Government or any agency thereof.

\author{
PACIFIC NORTHWEST NATIONAL LABORATORY \\ operated by \\ BATTELLE \\ for the \\ UNITED STATES DEPARTMENT OF ENERGY \\ under Contract DE-AC05-76RL01830
}

Printed in the United States of America
Available to DOE and DOE contractors from the Office of Scientific and Technical Information,
P.O. Box 62, Oak Ridge, TN 37831-0062;
ph: (865) 576-8401
fax: $(865)$ 576-5728
email: reports@adonis.osti.gov

\begin{abstract}
Available to the public from the National Technical Information Service, U.S. Department of Commerce, 5285 Port Royal Rd., Springfield, VA 22161 ph: (800) 553-6847 fax: $(703) 605-6900$ email: orders@ntis.fedworld.gov online ordering: http://www.ntis.gov/ordering.htm
\end{abstract}

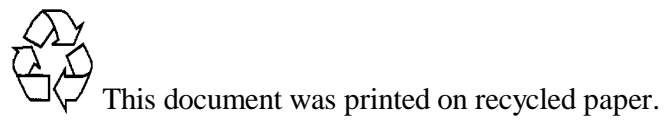




\section{Hydrodynamic Modeling Study Analysis of Union Slough Restoration Project in Snohomish River, Washington}

Z Yang

T Wang

December 2010

Prepared for

U. S. Army Corps of Engineers

Battelle_-Pacific Northwest Division

Richland, Washington 99352 



\section{Executive Summary}

To re-establish the intertidal wetlands with full tidal interaction and improve salmonid rearing habitat in the Lower Snohomish River estuary, the Everett Public Works Department restored the Union Slough project site in 2007 by breaching the existing dike and constructing bridges across the breaches. Pacific Northwest National Laboratory (PNNL) was contracted by the U.S. Amy Corps of Engineers to conduct a modeling study to evaluate additional project design scenarios at the restoration site for potential improvement of drainage conditions. In this study, a three-dimensional Snohomish River estuary model previously developed by PNNL was updated with fine-grid resolution for the Union Slough project site and validated with observed water level data collected in the project site and Union Slough. The drainage area percentage throughout entire range of tidal conditions was predicted for a number of proposed restoration alternatives.

This study report summarizes the modeling approach, the data used, model validation, and model application results. The structure of the report is as follows. The methodology of the study is described in Section 2. Model validation to the new existing condition of the project site is presented in Section 3. Error statistics for model validation and uncertainty of the model analysis are provided in Section 4. Model applications to proposed restoration scenarios are presented in Sections 5 and 6. A summary of this study and recommendations are provided in Section 7. References are given in Section 8. 



\section{Acronyms}

2D and 3D two dimensional and three dimensional

EPWD Everett Public Works Department

FVCOM finite-volume unstructured hydrodynamic model

MAE mean absolute error

ME mean error

NAD North American Datum

NAVD North American Vertical Datum

PNNL Pacific Northwest National Laboratory

PSLC Puget Sound Lidar Consortium

RE relative error

RMSE root mean square error

USACE U.S. Amy Corps of Engineer

UTM Universal Transverse Mercator 



\section{Contents}

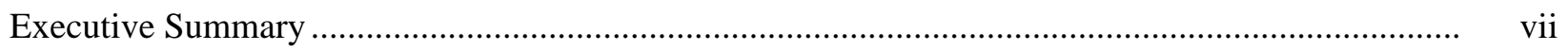

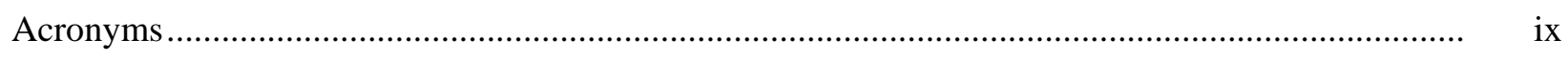

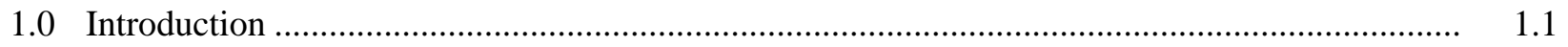

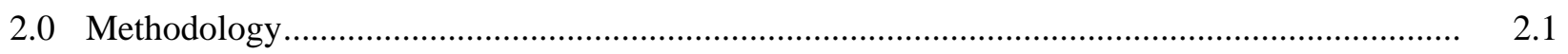

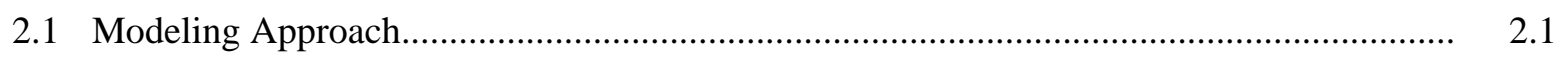

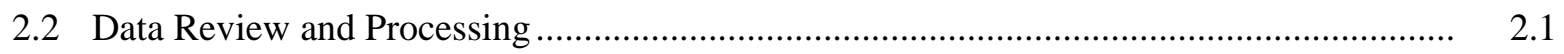

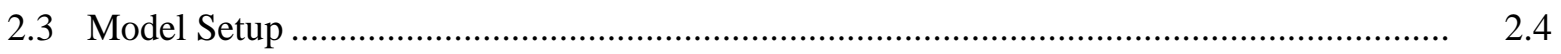

3.0 Model Validation for New Existing Conditions ............................................................

4.0 Model Accuracy and Uncertainty Analysis ................................................................. 4.1

5.0 Model Application to Bridge Removal Scenarios ................................................................ 5.1

5.1 Scenario I-Removal of North Bridge ...................................................................... 5.1

5.2 Scenario II-Removal of North and South Bridges................................................... 5.6

5.3 Scenario III—Removal of South and Central Bridges .................................................... 5.8

5.4 Scenario IV—Removal of All Bridges ..................................................................... 5.9

6.0 Low Tide Channel and All Bridges Removed Scenario.................................................... 6.1

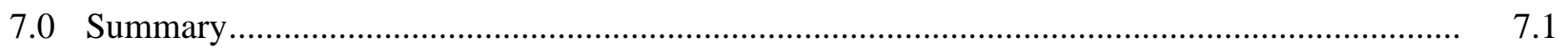

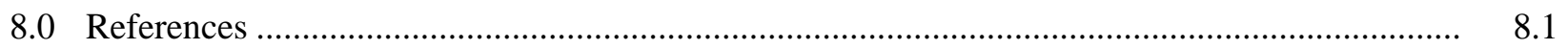




\section{Figures}

1.1. Union Slough Project Site (Aerial Photo Taken at Low Tide in August 2009) ........................ 1.2

2.1. Bathymetry Survey Data Points and Drainage Channel Cross-sections ................................. 2.2

2.2. Ground Elevation Distributions of USACE and City of Everett Bathymetry Survey Data and PSLC Lidar Data.

2.3. Observed Water Surface Elevations Inside the Project Site (HOBO-1 to HOBO-4) and in Union Slough (HOBO-5)

2.4. Updated Hydrodynamic Model Grid of Snohomish River and Forcing Stations ..................... 2.5

2.5. Zoom-in Model Grid and Bathymetry Distribution in Union Slough Project Site ................... 2.6

2.6. Snohomish River Discharge at USGS Gauge 12150800 ................................................... 2.7

2.7. Water Surface Elevations Obtained from XTide Prediction .................................................. 2.8

2.8. Wind Stick Plot at Everett/Paine Field Meteorological Station ............................................ 2.9

3.1 Comparisons of Predicted and Observed Water Surface Elevation at HOBO Stations .............. 3.1

3.2. Comparison of Predicted Inundation Area and Field Survey................................................ 3.4

3.3. Snapshots of Depth-Averaged Velocity and Wetted Areas at Ebb and Flood Tides ................. 3.5

3.4. Time Series of Drainage (Dry) Area Percentage in the Project Site Under Existing Conditions

3.5. Cumulative Ground Surface Area vs. Ground Elevation in the Project Site............................ 3.7

4.1. Uncertainty Range of Predicted Drainage Area Percentage .................................................. 4.3

5.1. Comparison of Model Grids near North Bridge Area ........................................................ 5.2

5.2. Drainage Area Percentage Under North Bridge Removal Conditions .................................... 5.2

5.3. Water Level Comparisons between Existing and North Bridge Removal Conditions at Station N1.....

5.4. Comparison of the Maximum Drainage Areas Under Existing and North Bridge Removal Conditions.

5.5. Comparisons of Depth-average Velocities at Ebb and Flood Tides Under Existing and North Bridge Removal Conditions.

5.6. Comparison of Model Grids near South Bridge Area ........................................................... 5.7

5.7. Drainage Area Percentage under North and South Bridge Removal Conditions...................... $\quad 5.8$

5.8. Comparison of Model Grids near Central Bridge Area ...................................................... 5.9

5.9. Drainage Area Percentage Under Central and South Bridge Removal Conditions .................. $\quad 5.9$

5.10. Drainage Area Percentage Under All Bridge Removal Conditions ......................................... 5.10

5.11. Predicted Water Levels at Station N1, C1, and S1 Under Existing, North Bridge Removal, and All Bridges Removed Conditions.

6.1. Model Grid Configuration for Low Tide Channel and All Bridges Removed Conditions .

6.2. Comparison of Model Bathymetry Between Bridge Removal and Bridge Removal+Low Tide Channel Conditions.

6.3. Drainage Area Percentage Under Bridge Removal+Low Tide Channel Conditions ................. 6.3

6.4. Predicted Water Levels at Stations N1, C1, and S1 under Existing and Bridge Removal+Low Tide Channel Conditions. 
6.5. Comparison of Drainage Areas and Water Depths Between Bridge Removal and Bridge Removal+Low Tide Channel Conditions.

6.6. Comparisons of Depth-average Velocities at Ebb and Flood Tides Under Existing and Bridge Removal+Low Tide Channel Conditions

\section{Tables}

4.1. Station-Average, Water-Level Error Statistics for Model Validation.

4.1 



\subsection{Introduction}

The Snohomish River is the second largest discharge into Puget Sound. It enters Puget Sound near Everett, WA, through a braided estuary that provides vital nearshore habitat supporting downstream salmon migration runs. To improve and restore nearshore habitat and fish migration pathways in the Snohomish River, the Tulalip Tribes, the city of Everett, Snohomish County, and Port of Everett are evaluating the feasibility of multiple restoration projects, including the Union Slough Restoration Project by the City of Everett. To better understand the hydrodynamic conditions in the Snohomish River and to provide guidance to the nearshore restoration efforts, Battelle developed a three-dimensional (3D) hydrodynamic model for the Snohomish River and the associated restoration sites. This was accomplished using the finite-volume unstructured hydrodynamic model FVCOM. The model was calibrated with field-observed tide and current data for the period of 10/13/2006 to 10/27/2006. Results of model development, calibration and applications to restoration project conditions were provided previously in the project study report (Yang and Khangaonkar 2007).

The Everett Public Works Department (EPWD) restored the Union Slough project site in 2007. The project site was restored by breaching the existing dike and constructing bridges across the breaches at three locations (1.1). The objective of the restoration project is to re-establish the intertidal wetlands with full tidal interaction with Union Slough and improve salmonid rearing habitat. It was anticipated that the restored project site would be fully inundated during high tides and drained "completely" (within 5\% or less of the total surface area covering the standing water [JCF Jones \& Stokes 2009]). However, due to design changes during construction, a majority of each breach ended up with an elevation of $4.0 \mathrm{ft}$ NAVD88, which is $2 \mathrm{ft}$ higher than the original design. As a result, the project site could not drain as efficiently as desired. A significant portion of the site is lower than $4.0 \mathrm{ft}$ NADV88.

To improve the drainage conditions, the U.S. Amy Corps of Engineers (USACE) contracted Pacific Northwest National Laboratory (PNNL) to conduct a modeling study to evaluate additional project design scenarios at the restoration/mitigation site during low tide and to provide recommendations for finishgrade elevations to achieve the desired drainage. This could be accomplished with the Snohomish River hydrodynamic model developed previously. Specifically, the modeling analysis consists of three components:

- Model validation to new existing condition. The Snohomish River model developed in 2007 did not consider the restored Union Slough project in its present state. In this study, the model was modified to include the restored Union Slough project as part of the existing condition and validated against field data (water level only) collected from May 27, 2009, to June 26, 2009.

- Bridge Removal Scenarios. A series of model simulations were conducted to evaluate the effectiveness of drainage at the project site with different combinations of bridge-removal scenarios.

- Low-Tide Channel Analysis. This task was conducted to further improve the drainage conditions at the project site when the bridge-removal actions alone could not achieve the desired drainage during low tides.

This study report summarizes the modeling approach, the data used, model validation, and model application results associated with the above three tasks. Error statistics for model validation are calculated, and the uncertainty of the model analysis is addressed. A time series of water surface 
elevations and the percentage of the drainage area at various locations inside the project site are presented. Horizontal two-dimensional (2D) distributions of depth-average velocity vectors and wetted areas during different tidal phases are generated and discussed. The efficiency of the proposed restoration scenarios is discussed, and recommendations for potential improvement of drainage in the project site are also provided in the report.

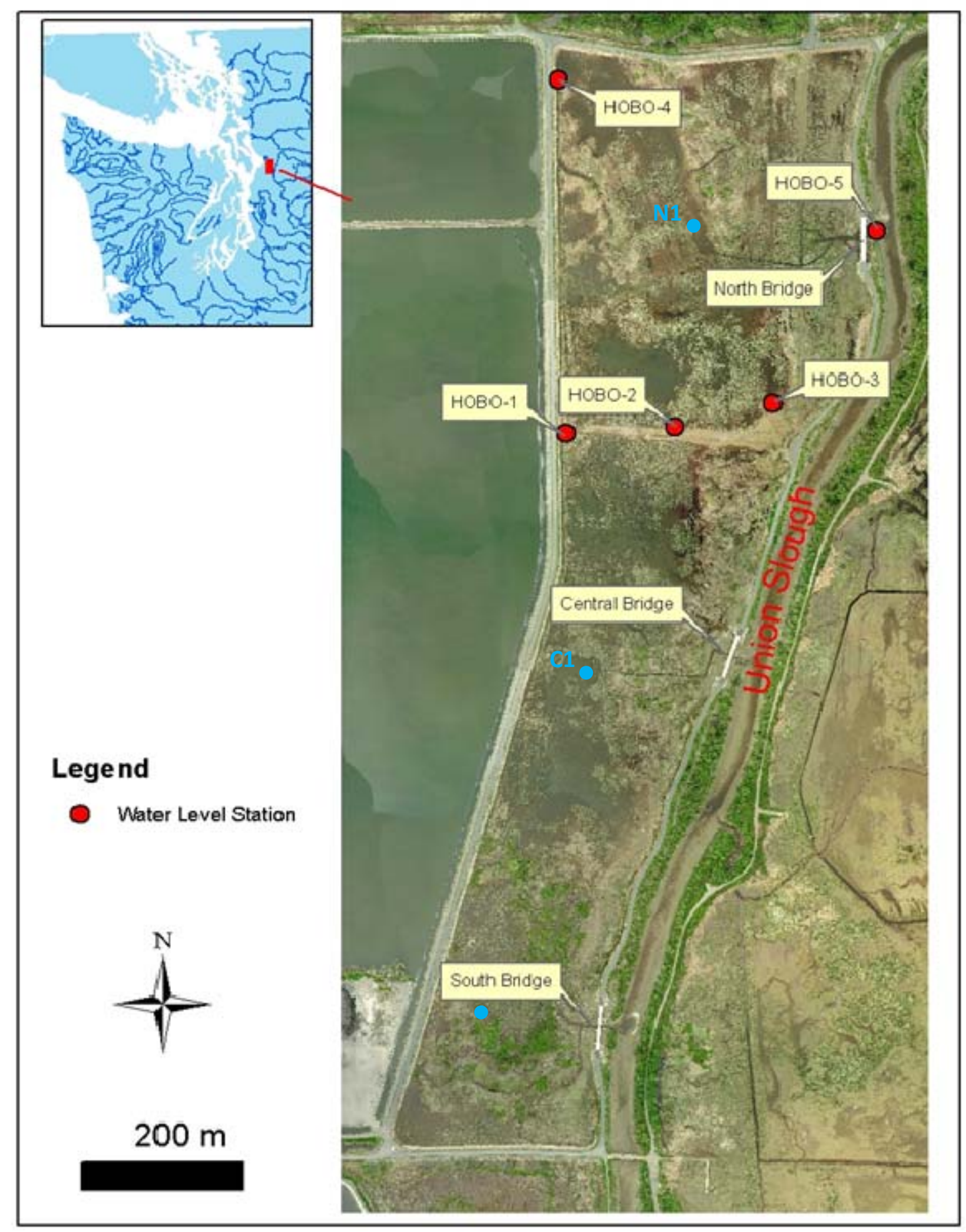

1.1. Union Slough Project Site (Aerial Photo Taken at Low Tide in August 2009) 


\subsection{Methodology}

\subsection{Modeling Approach}

PNNL proposed achieving the project objectives through the following steps:

- Use of existing model—most recently updated with Tulalip lidar data near the mouth of Snohomish River

- Site visit of Union Slough project under the new existing conditions-3/19/2010

- Modification of existing Snohomish hydrodynamic model to represent the new existing conditionsThe Snohomish River model was updated by including the current Union Slough restoration/mitigation site using survey information from the City of Everett and their consultant (JCF Jones \& Stokes) in 2008, topographic survey of site was performed by Perteet in May-June 2009, and the structural plan designed by the U.S. Army Corps of Engineers, Seattle District (Corps).

- Validation with new exiting conditions-A model calibration of existing conditions at the restoration/mitigation site was conducted using water surface elevations measured at four locations within the mitigation site and at one location on Union Slough for a 1-month period from 27 May 2009 to 26 June 2009.

- Application to new restoration alternatives-bridge removals and low tide channels.

\subsection{Data Review and Processing}

The following three groups of data are required for this study:

1. Bathymetric data for model grid update

2. Water level data for model validation

3. Model forcing data for model setup.

The first two groups of data are presented and discussed in this section. Model forcing data will be discussed in the next section along with model setup and validation.

Bathymetric data were obtained from following resources:

- USACE data-This dataset has ground surface data originally from USACE plans for the levee project. The data were provided in an AutoCAD file format ("union_base3d.dwg") (2.1—Left Panel).

- City of Everett data-This includes two bathymetric datasets that are in AutoCAD format. The "2969-2 point.dwg" file is the point data from the 2009 ground survey. The "Smith Island sed points.dwg" is the result of a survey conducted in July 2008 (also see 2.1—Left Panel).

- Drainage Channel data-During the site visit, the project team felt it was important to obtain accurate drainage channel geometries to develop the model. The drainage-channel data were collected by the City of Everett after the site visit. The dataset contains the cross-sectional geometry survey results for the drainage channels near the three bridges (2.1—Right Panel). 
- Lidar data-The Lidar data were obtained from Puget Sound Lidar Consortium (PSLC) (2.2 - Right Panel). The data were collected in July 2009 by Watershed Sciences, Inc. (Watershed Sciences 2009). The lidar data were used for reference and filling gaps only in this study. A comparison between lidar data and USACE/City data (2.2-Left Panel) indicated that in many places, lidar data may have higher elevations than the USACE/City survey data.

Month-long, continuous water-level data were collected during the period from May 27, 2009, to June 26, 2009, in the project site as well as in Union Slough (2.3). Four stations were located in the northern region of the project site, and one station was located in Union Slough just outside of the northern bridge (1.1). Data were sampled at 10-minute intervals. No data were collected in the central and southern areas of the project site. Water surface elevation distributions inside the project site were very similar and reached the same high water level as in Union Slough during high tides. However, water levels in the project site did not drop to the same low-tide levels as seen in Union Slough because of the higher ground elevations within the project site. The water level data were used for the updated model validation with the breaching project site in place.
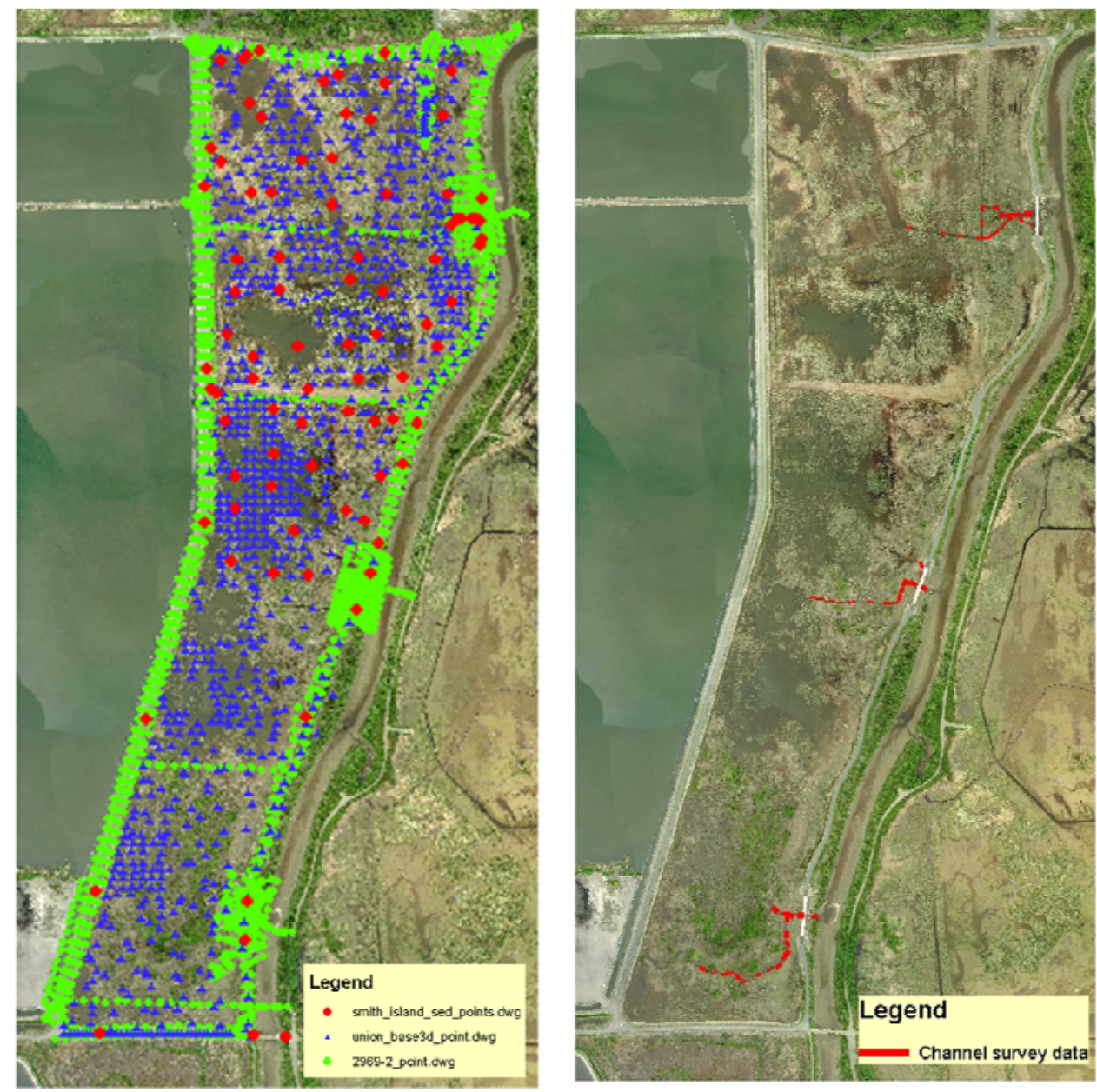

2.1. Bathymetry Survey Data Points (Left Panel) and Drainage Channel Cross-sections (Right Panel) 


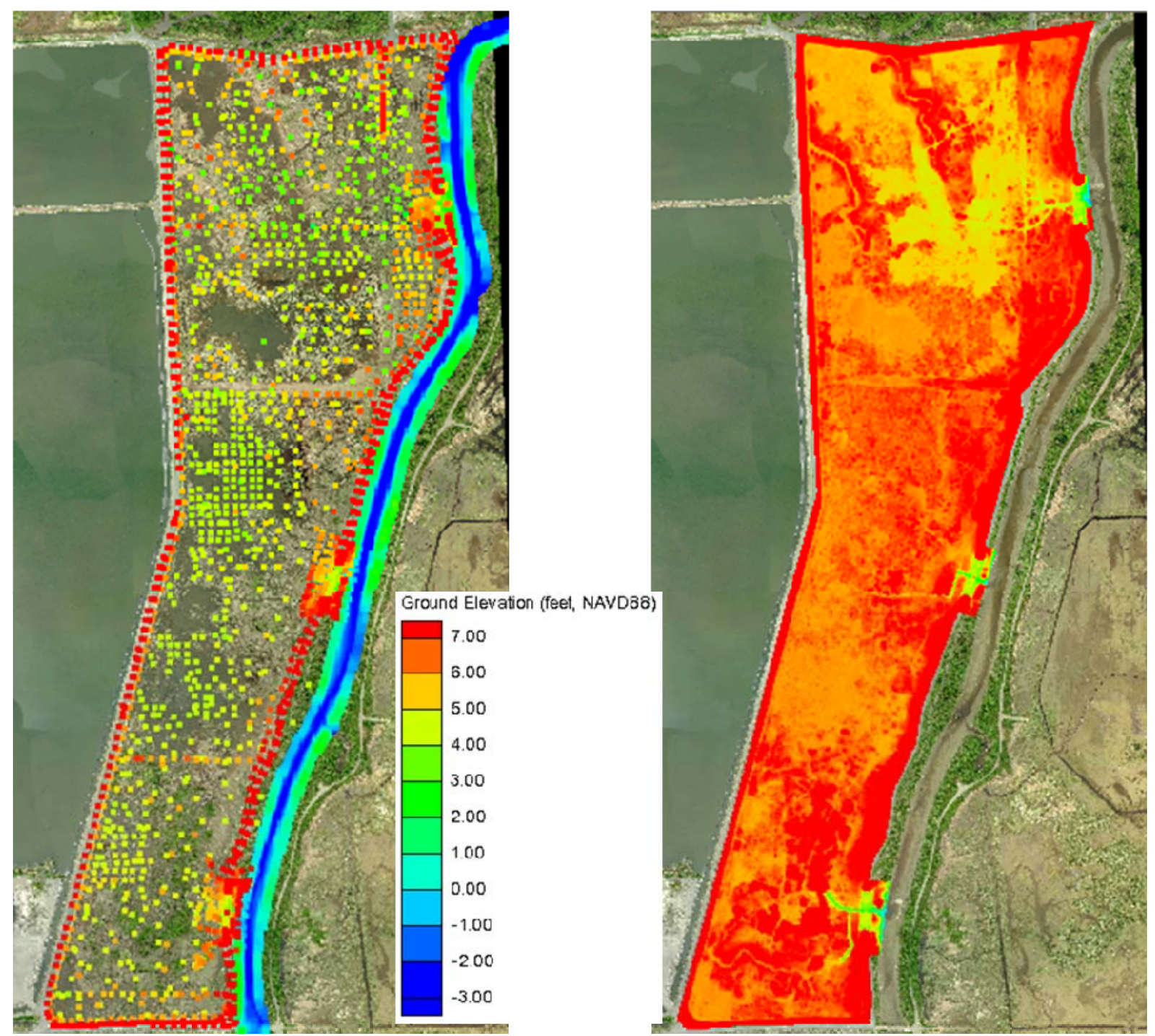

2.2. Ground Elevation Distributions of USACE and City of Everett Bathymetry Survey Data (Left Panel) and PSLC Lidar Data (Right Panel) 


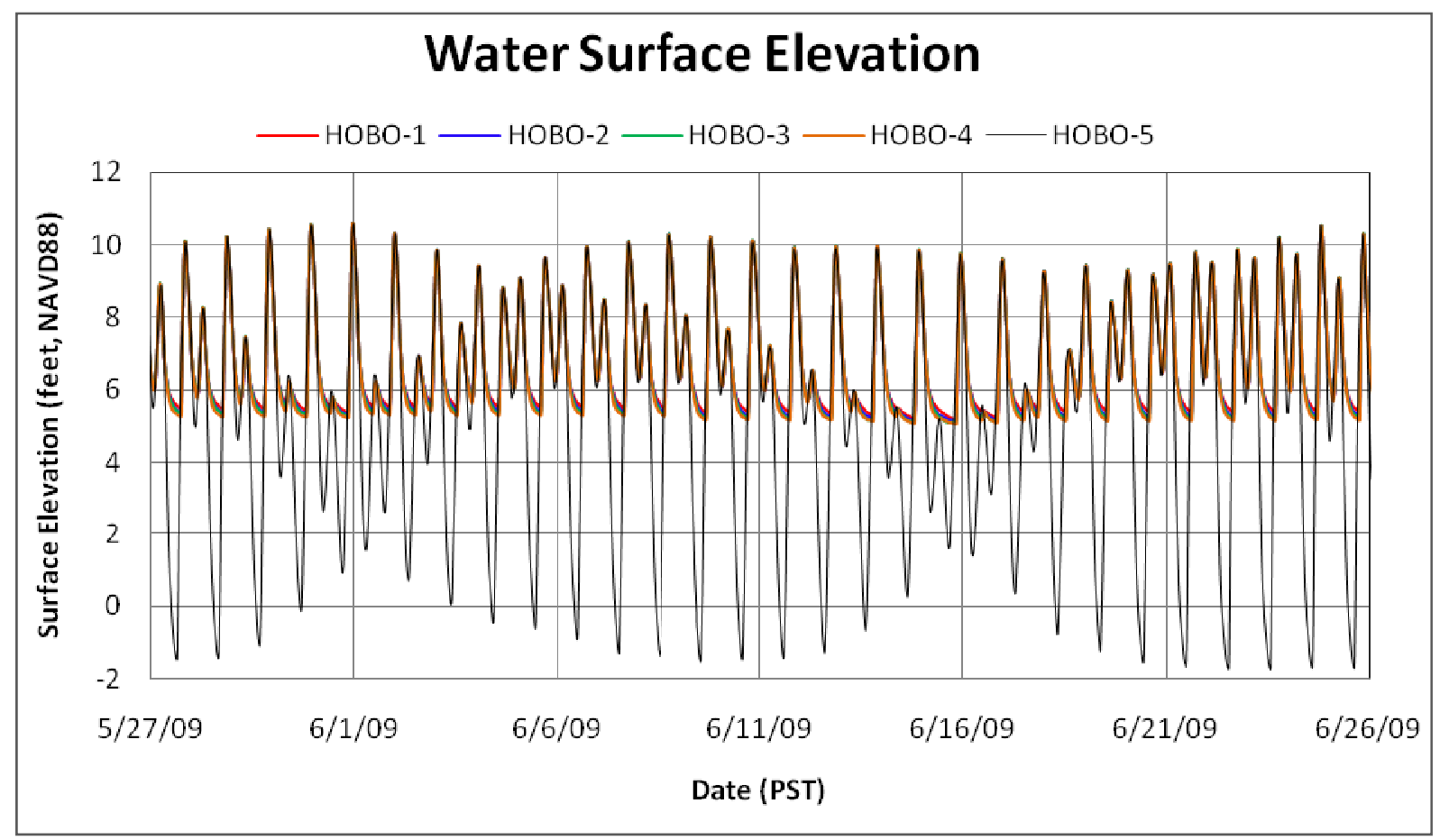

2.3. Observed Water Surface Elevations Inside the Project Site (HOBO-1 to HOBO-4) and in Union Slough (HOBO-5) (see station locations in 1.1)

\subsection{Model Setup}

The hydrodynamic model setup generally consists of two major components: 1) grid development and 2 ) boundary specifications. The model grid for this study was developed based on the latest Snohomish River model grid with updated bathymetry near the mouth of the river using lidar data collected by the Tulalip Tribes for the Qwuloolt project. The existing hydrodynamic model grid of the Snohomish River was modified and refined for the Union Slough project site. The presence of the north, central, and south bridges/breaches in the restored Union Slough project was incorporated into the model grid. The entire model grid with the Union Slough project site is shown in 2.4. The model bathymetry in the project site was constructed based on USACE and City of Everett data shown in 2.1. The drainage channel data were used to manually modify the drainage channel elevations near the three bridges. In this study, as suggested by the project team, lidar data were not used for model elevation interpolation. However, they were used as a reference check when the elevation survey data were found to be significantly off from the high-resolution aerial photo. Detailed model grid layouts near the dike breaches and bathymetry distribution in the project site are shown in 2.5.

The refined Snohomish River model grid for the existing condition consists of 44,885 elements and 24,213 nodes in the horizontal plane. Ten uniform vertical layers were specified in the water column in a sigma-stretched coordinate system. The model was set up in Universal Transverse Mercator (UTM) North American Datum (NAD) 83 (Zone 10) coordinates in the horizontal plane with reference to North American Vertical Datum 88 (NAVD 88) in the vertical direction. 


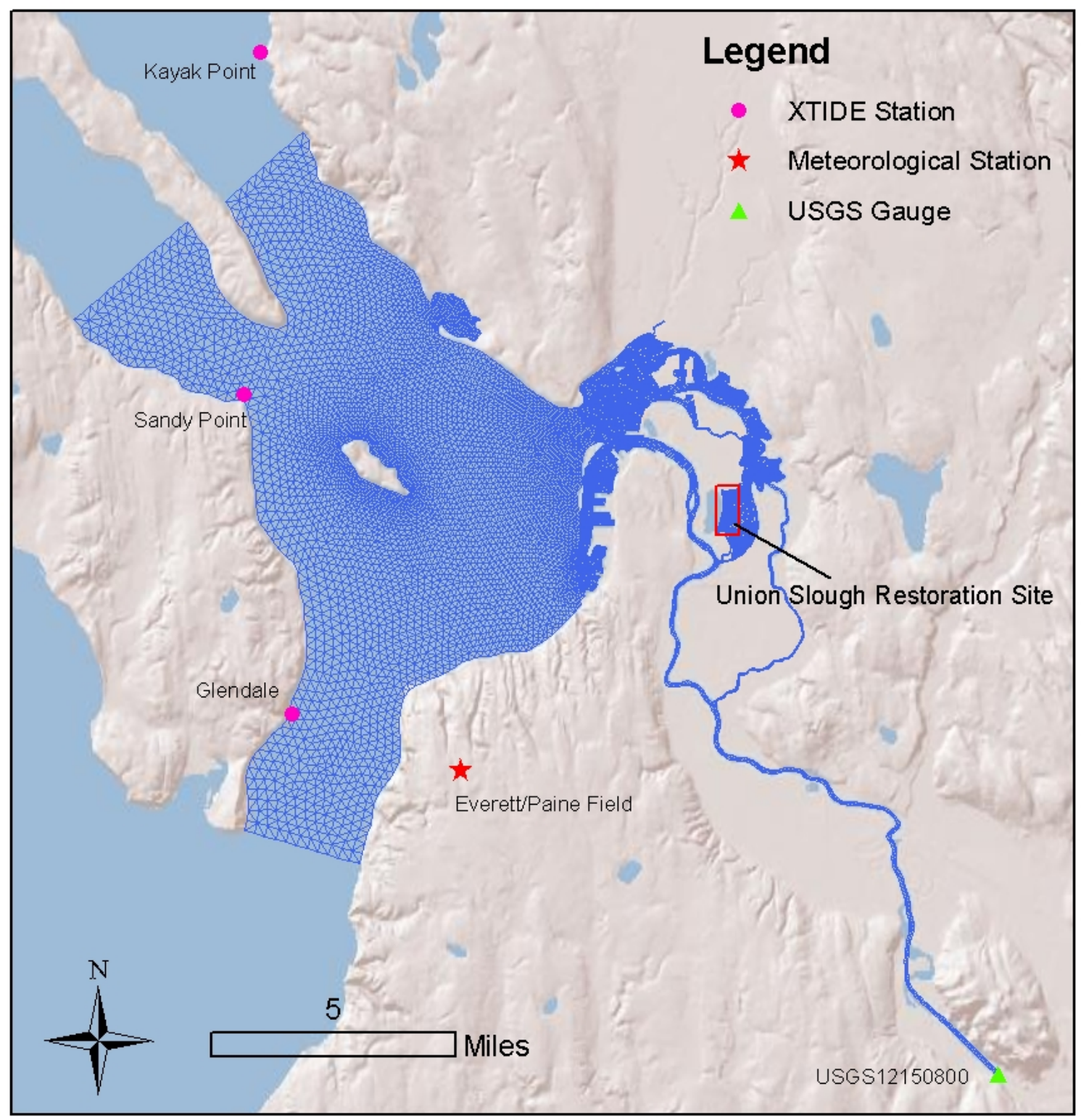

2.4. Updated Hydrodynamic Model Grid of Snohomish River and Forcing Stations 

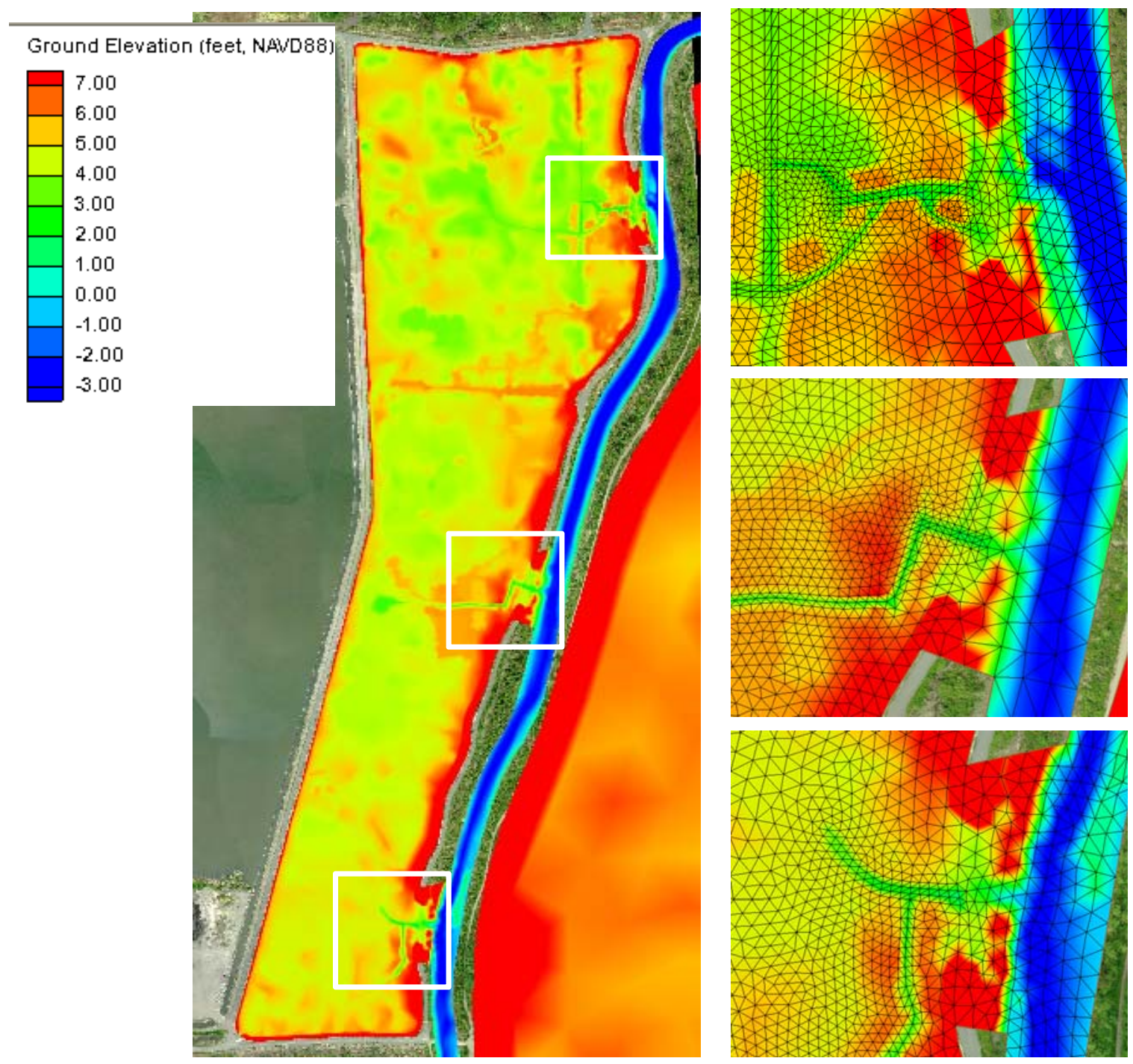

2.5. Zoom-in Model Grid and Bathymetry Distribution in Union Slough Project Site

Model boundary conditions were specified using three types of forcings:

- River inflow

- Tides

- Wind speed and direction.

River-inflow data for the model validation period (5/27/2009-6/26/2009) were obtained from the real-time USGS gauge 12150800 near the City of Monroe (2.6). The flow rate for the model validation period varied from around 7,000 to $24,000 \mathrm{cfs}$. The mean flow rate for the simulation period is 13,650 cfs, which was a little higher than the long-term, mean river flow of 9,480 cfs esimated from long-term gauge records. 


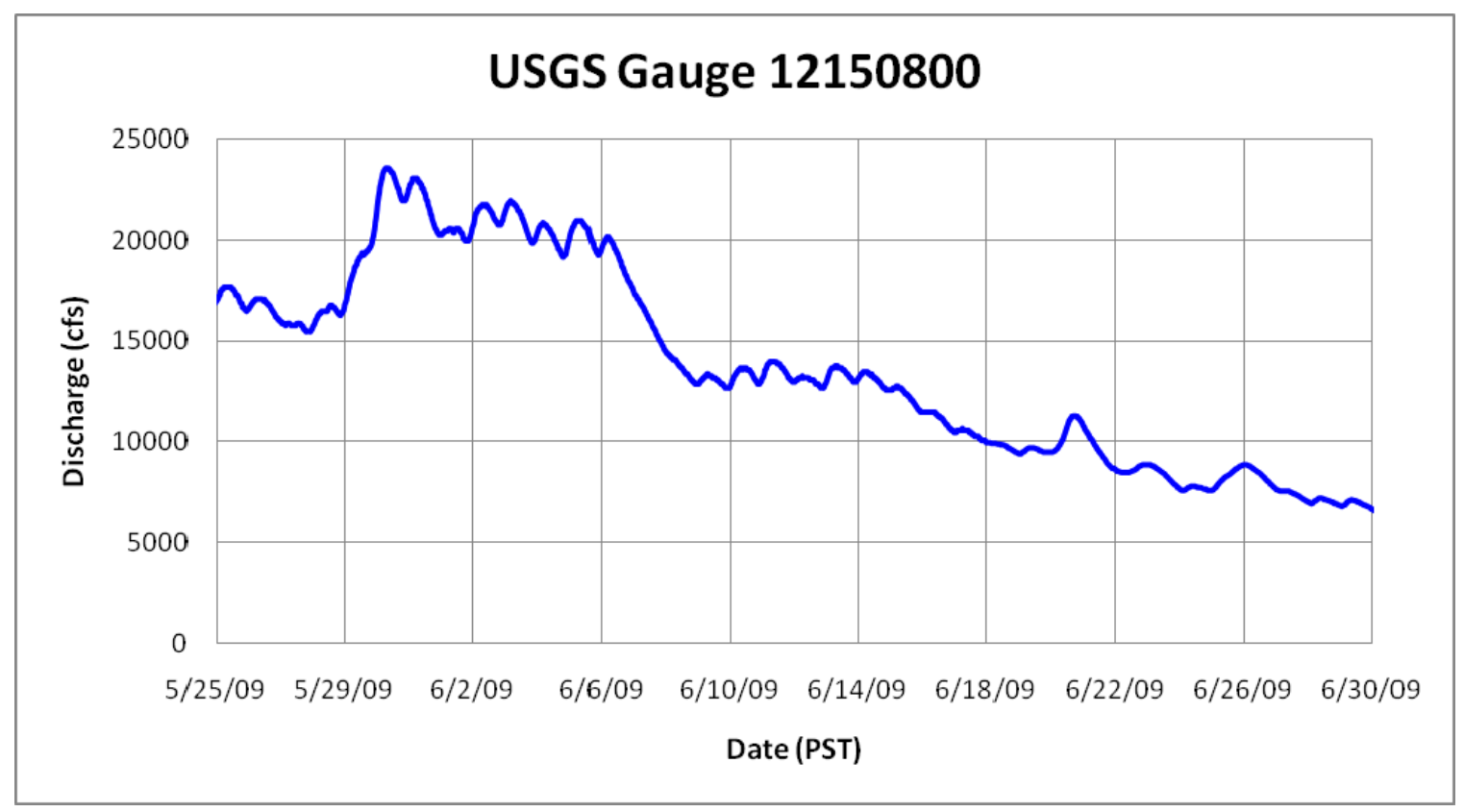

2.6. Snohomish River Discharge at USGS Gauge 12150800

Tidal elevations were specified along the open boundaries of the model. There are three open boundaries in the model domain: the southern open boundary connects to the Main Basin of Puget Sound; the northwest open boundary connects to the Saratoga Passage, and the northern boundary connects to Port Susan Bay (2.4). Predicted tides at Sandy Point, Glendale, and Kayak Point using XTide program (Flater 1996) were specified for the tidal elevation boundary conditions (2.7). 


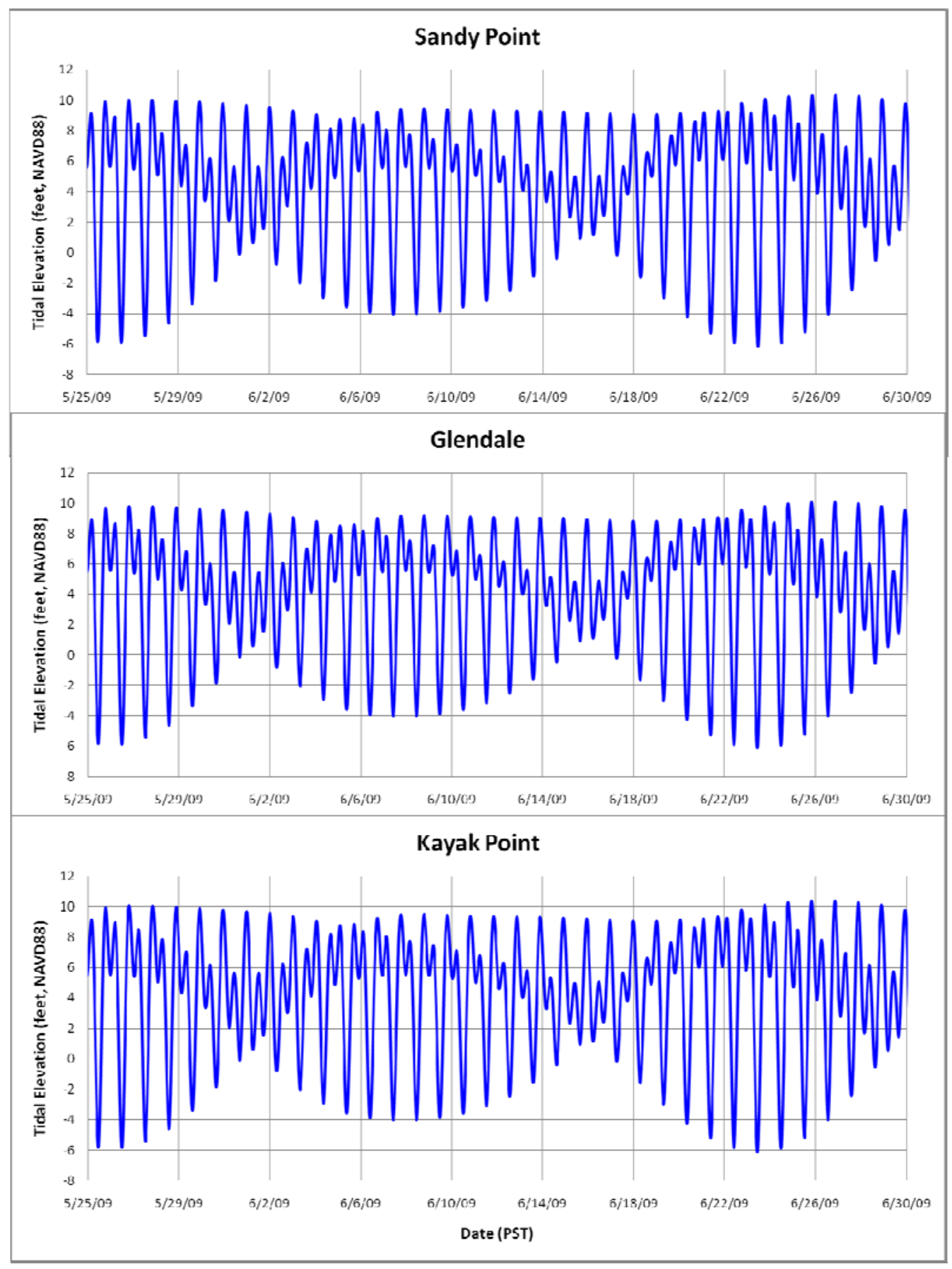

2.7. Water Surface Elevations Obtained from XTIDE Prediction 
Wind speed and direction were used to calculate the wind stress at the water surface. Wind data were specified uniformly in the entire model domain using osberved wind data from the Paine Field Airport near the City of Everett. The average wind speed for the simulation period was $1.9 \mathrm{~m} / \mathrm{s}$, and wind directions were towards the south most of the time. Episodic southernly wind events with wind speeds greater than $5 \mathrm{~m} / \mathrm{s}$ were observed in the data $(2.8)$

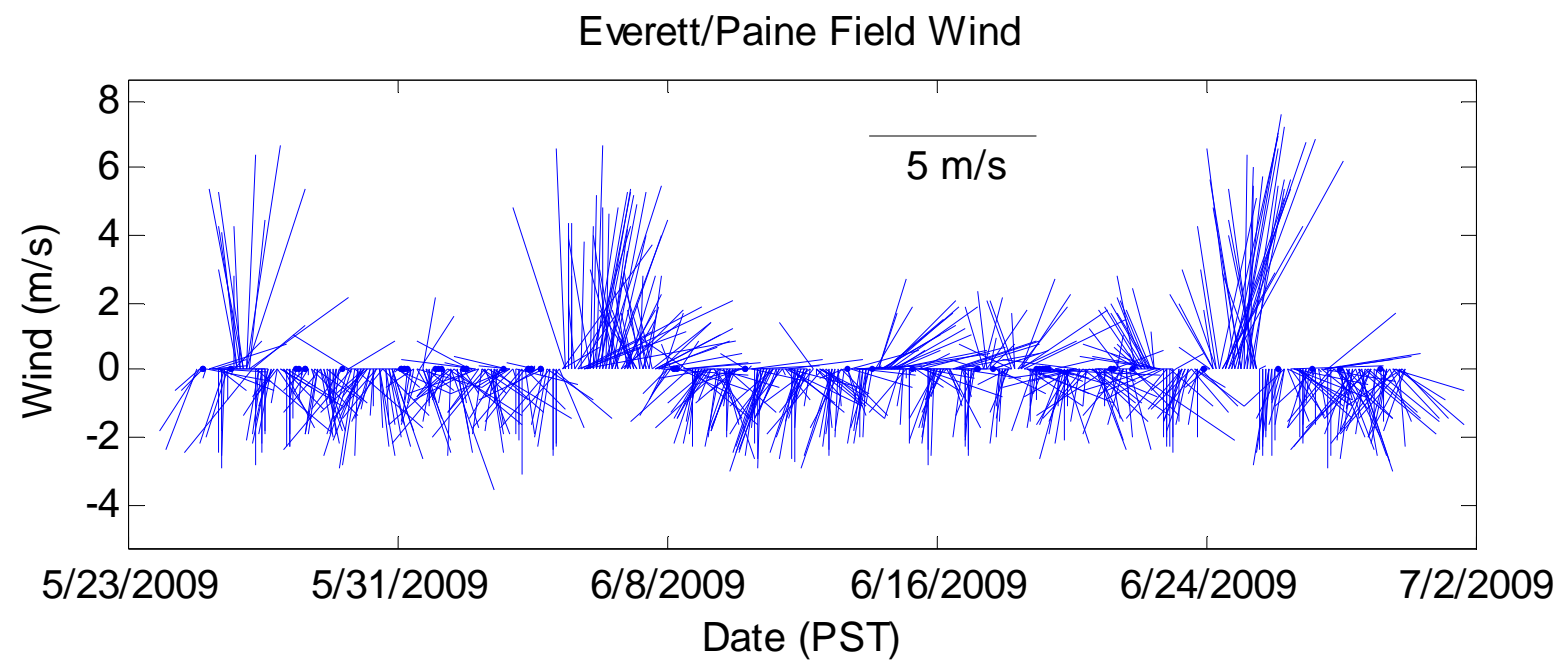

2.8. Wind Stick Plot at Everett/Paine Field Meteorological Station 



\subsection{Model Validation for New Existing Conditions}

Two days of spin-up time were added to the simulation period such that the model reached dynamic equilibrium on 5/27/2009. Because of the fine-grid resolution (2-3 meters), the model run-time step was 0.5 seconds, and model results were output hourly for post-processing. Predicted water surface elevations at all five monitoring stations (HOBO-1 to HOBO-5) were compared to the observations (3.1a-e). Model results matched the observed data reasonably well. The model re-produced the general tidal features observed in the data, such as the spring-neap cycle and diurnal inequality (3.1e). Within the project area, predicted tidal ranges were in good agreement with the observed data, especially the elevated water levels during low tide periods due to higher ground elevations and insufficient drainage in the project site. During low tides, predicted water levels tended to drop a little faster than the observation levels. The difference was primarily caused by the complex bathymetry distributions in the project site that could not be accurately represented in higher resolution using the available bathymetry survey data.

An inundation/drainage map during the low tide period for the project site was prepared by JCF Jones $\&$ Stokes and was based on field survey data. For a qualitative comparison, an inundation map was generated based on model results at 6:00 pm PST on 5/28/2009 during a low-tide period. 3.2 shows that the predicted distribution pattern of tidal inundation in the project site is very similar to the survey data, which confirms the capability of the model to predict tidal propagation in and out of the restored project site.

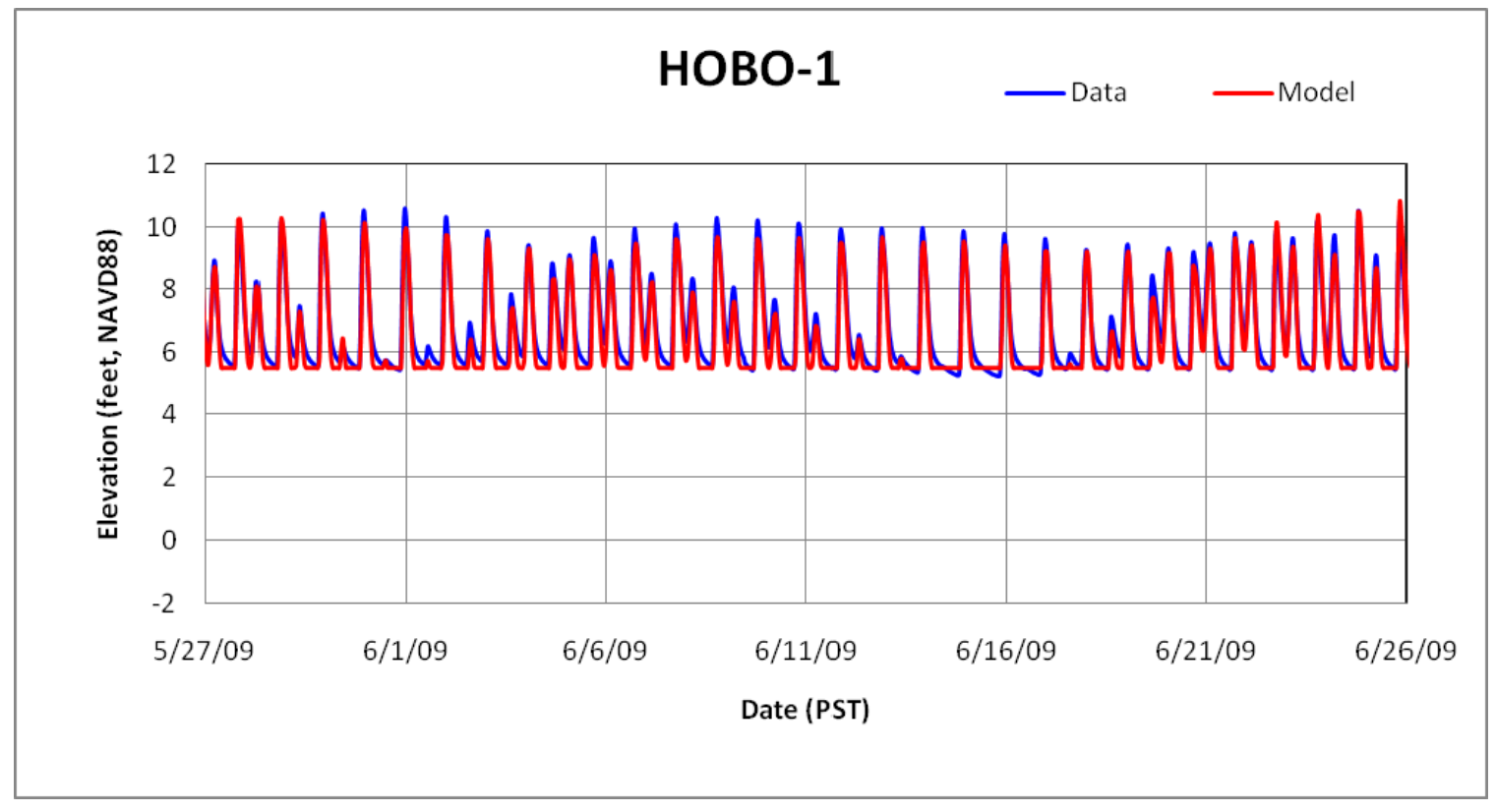

3.1(a). Comparisons of Predicted and Observed Water Surface Elevation at HOBO-1 


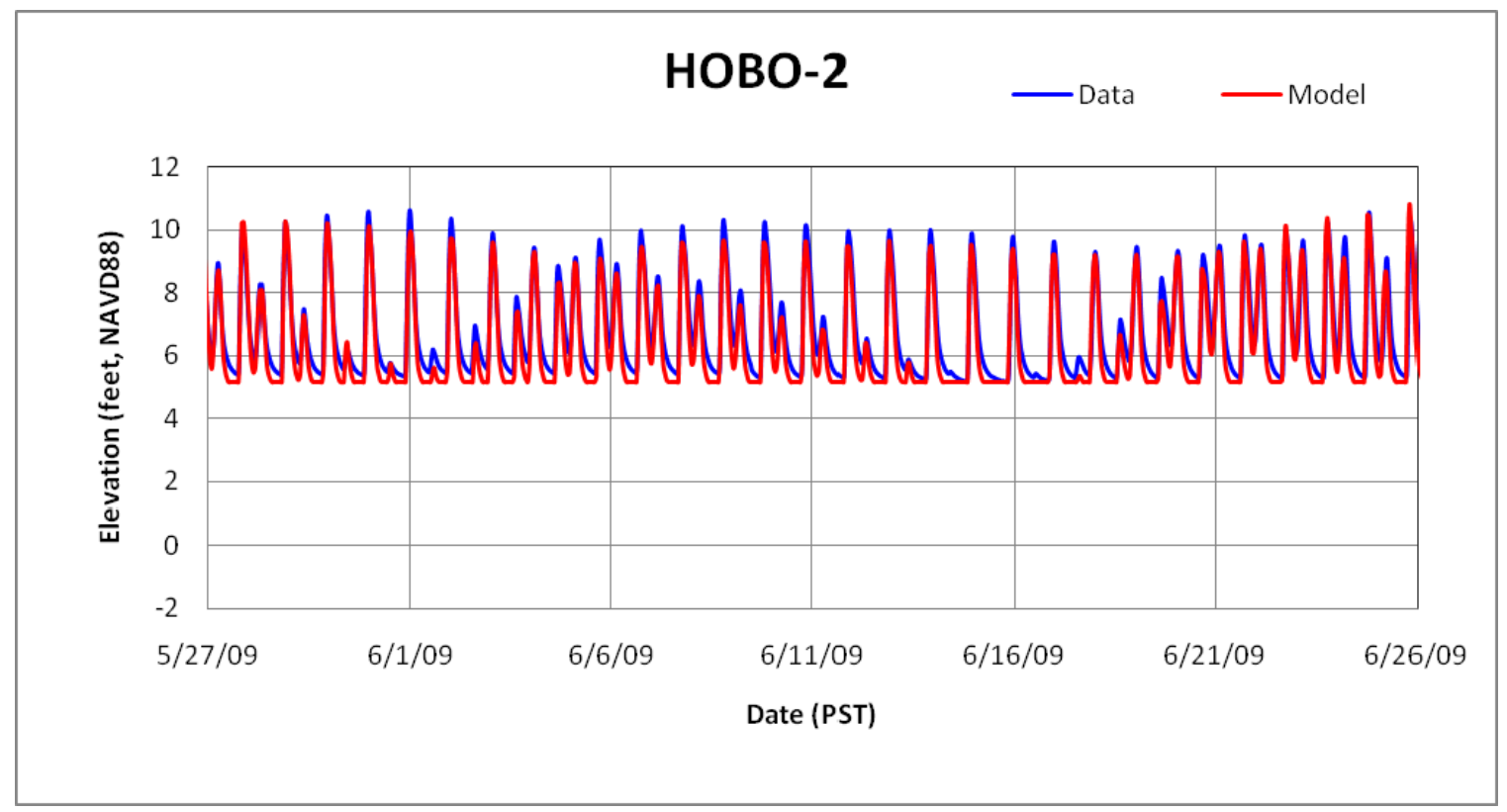

3.1(b). Comparisons of Predicted and Observed Water Surface Elevation at HOBO-2

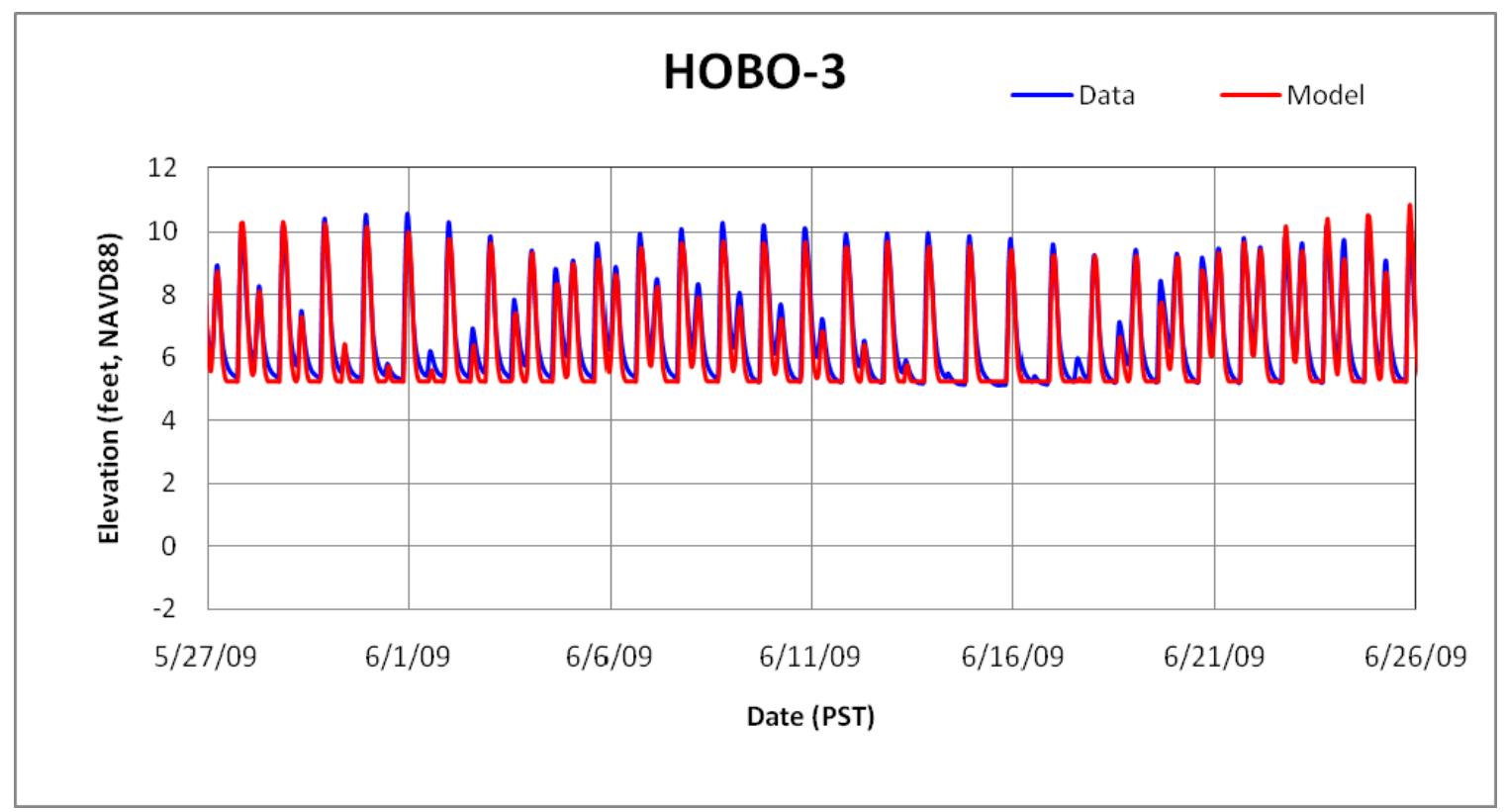

3.1(c). Comparisons of Predicted and Observed Water Surface Elevation at HOBO-3 


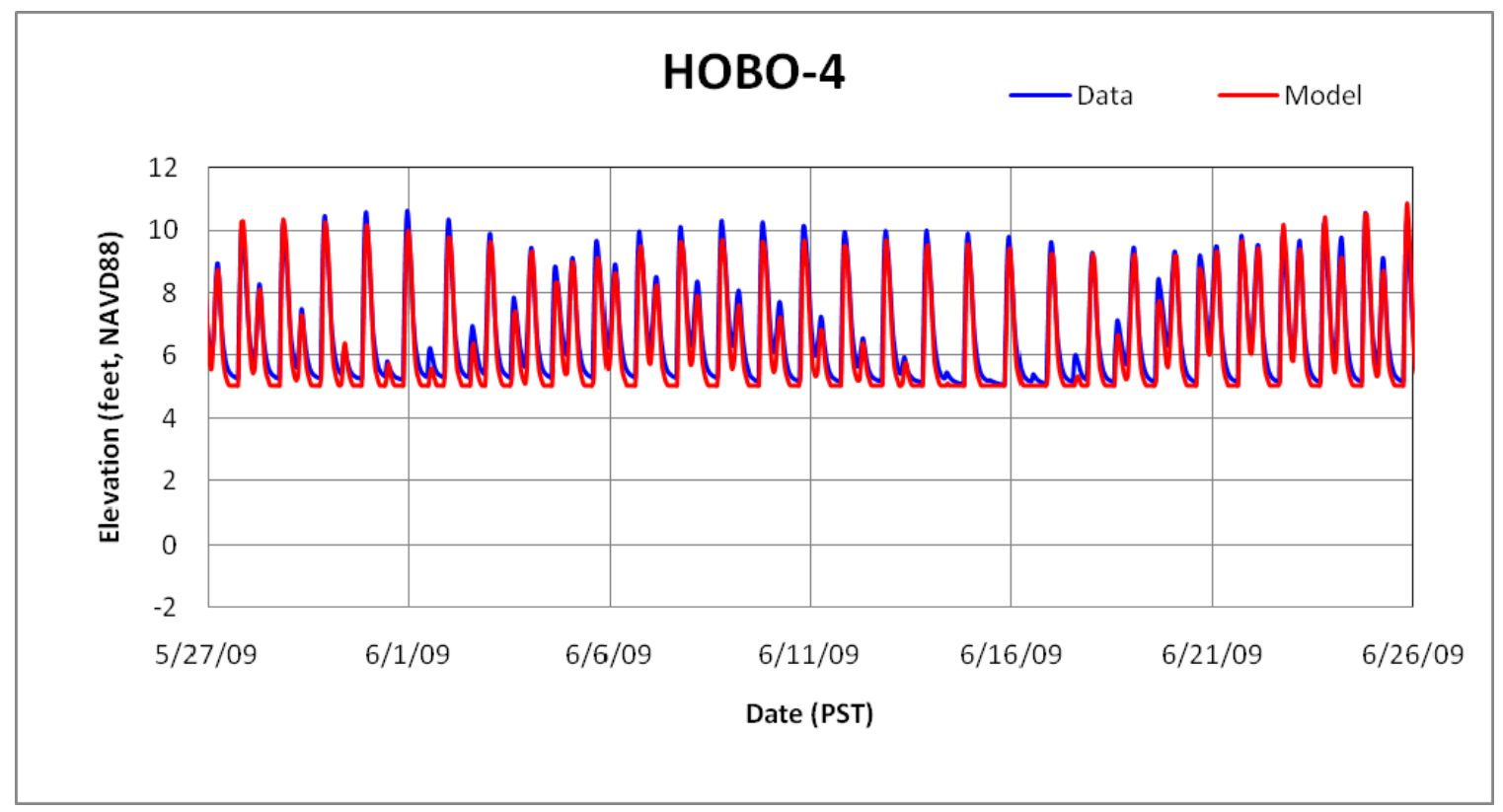

3.1(d). Comparisons of Predicted and Observed Water Surface Elevation at HOBO-4

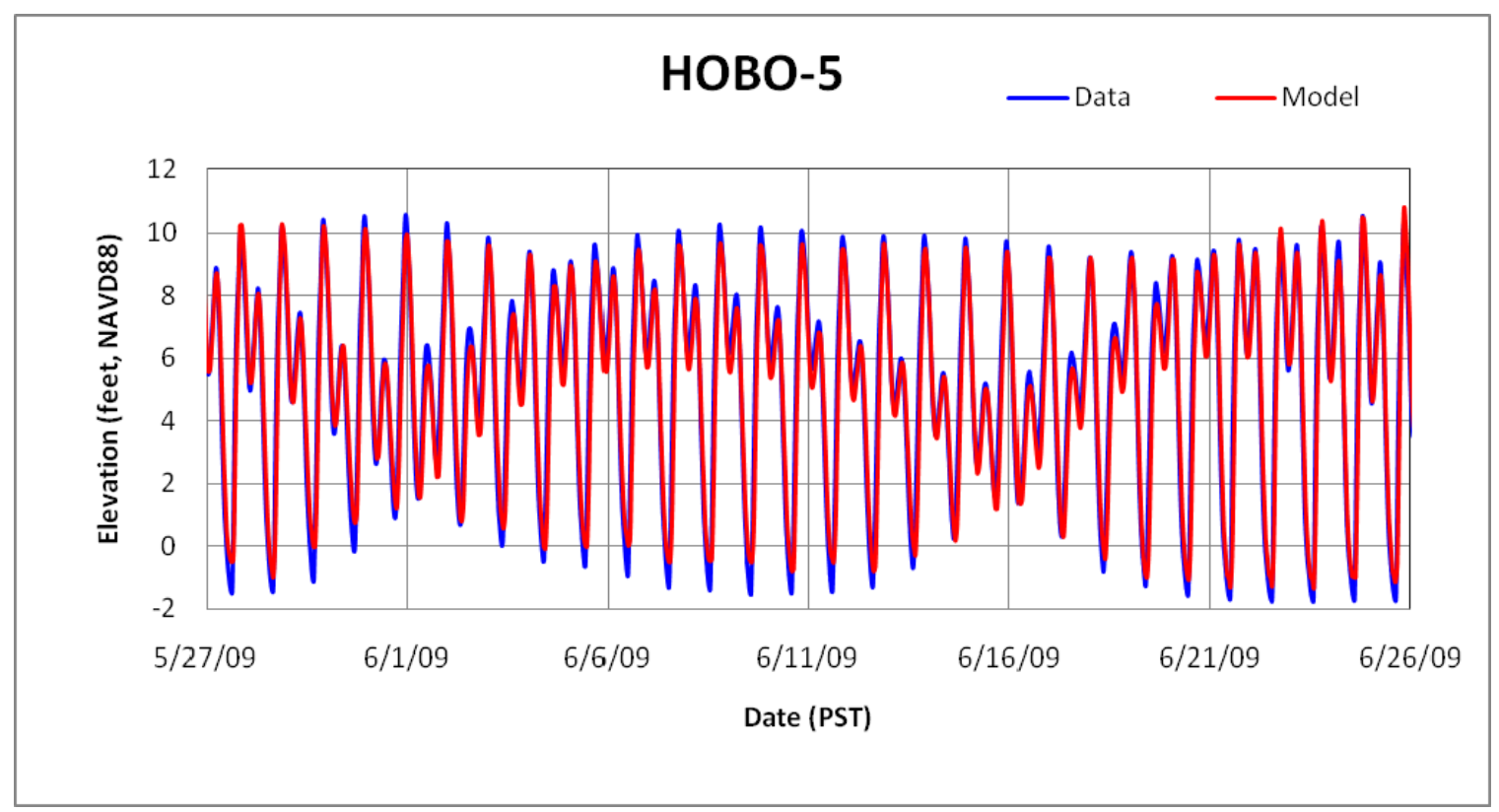

3.1 (e). Comparisons of Predicted and Observed Water Surface Elevation at HOBO-5

Although 3D velocity fields (10 layers) were simulated in the model, depth-average velocities were post-processed and presented. Snapshots of predicted horizontal 2D depth-average velocities at ebb and flood tides were generated (3.3a). During flood tide, a strong velocity occurred at all three bridge locations, especially at the north bridge. Eddies on both sides of the breaching opening were observed, a typical flow phenomena caused by the geometry effect - a narrow inlet connecting to an open waterbody. Velocities at ebb tides were lower than those at flood tide, as flows through the bridge were mainly driven by potential energy (water-level difference between the project site and Union Slough). In general, current magnitudes in the project site were small except near the bridge areas. It is also noted that 
currents in the Union Slough between the north and south bridges were smaller than that up- and downstream of Union Slough as a result of water being diverted into the project site. Closeup plots of velocity distribution at the bridge locations were provided in $3.3 \mathrm{~b}$.

Because the main interest of this modeling study is the efficiency of drainage after the restoration of the project site, the drainage area percentage with respect to the entire project site was calculated as a function of time. An element in the model is considered as dry when the water depth is less than 2 inches, which is the criterion used for simulating the wetting-drying processes in the model. The predicted drainage area percentage varied from nearly zero when the project was fully inundated at high tides to above $40 \%$ at low tides (3.4). The maximum percentage of the drainage area under the existing restored condition is much lower than the anticipated value of "95\%." The cumulative ground surface area below a given ground elevation in the project site increases dramatically from around $2 \%$ to almost $80 \%$ as the ground elevation changes from $3 \mathrm{ft}$ to $5 \mathrm{ft}$ NAVD88 (3.5). The flat distribution pattern of the ground surface area indicated that both the irregularity and the inner-connectivity would play an important role in drainage of the project site. The inefficient drainage in the existing restored condition was a combined result of narrow "choking" drainage channels near the bridges, irregular and complex bathymetry, and isolated ponding areas in the project site.
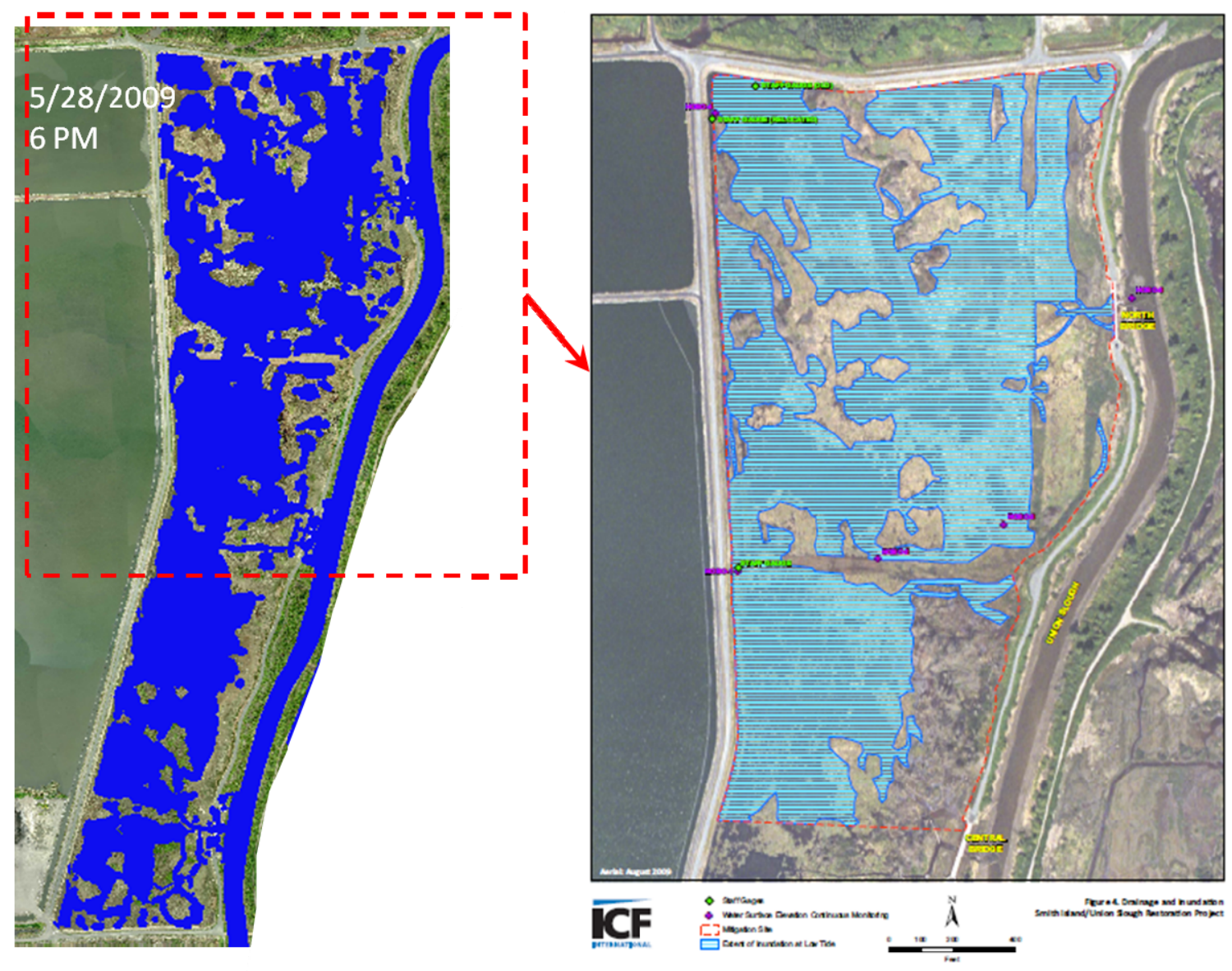

3.2. Comparison of Predicted Inundation Area (Left Panel—Blue Shaded Area) and Field Survey (Right Panel-Inundation Map Taken from JCF Jones \& Stokes) 

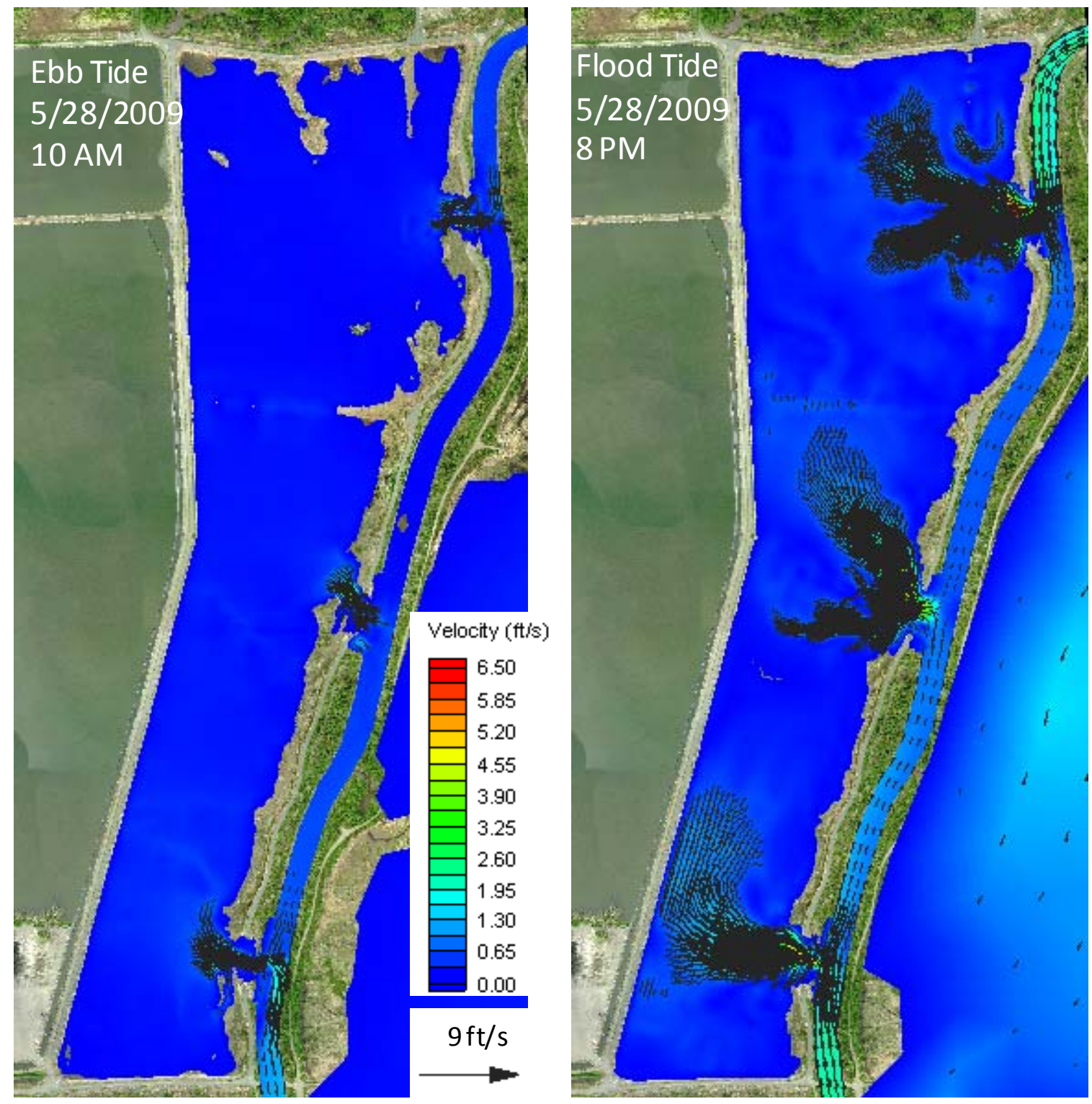

3.3a. Snapshots of Depth-Averaged Velocity and Wetted Areas at Ebb and Flood Tides 


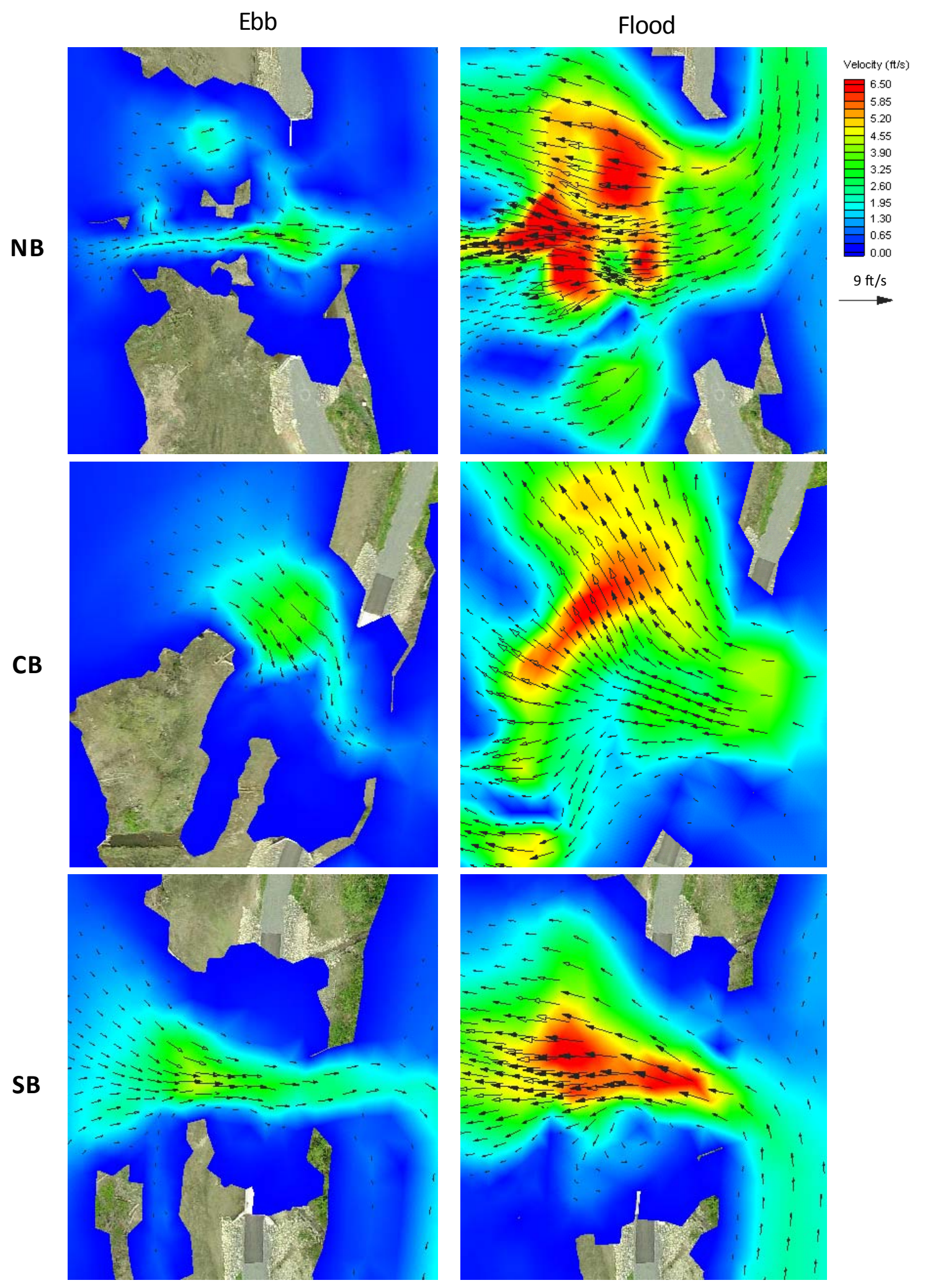

3.3b. Closeup Snapshots of Depth-Averaged Velocity and Wetted Areas at Ebb and Flood Tides near Bridge Locations 


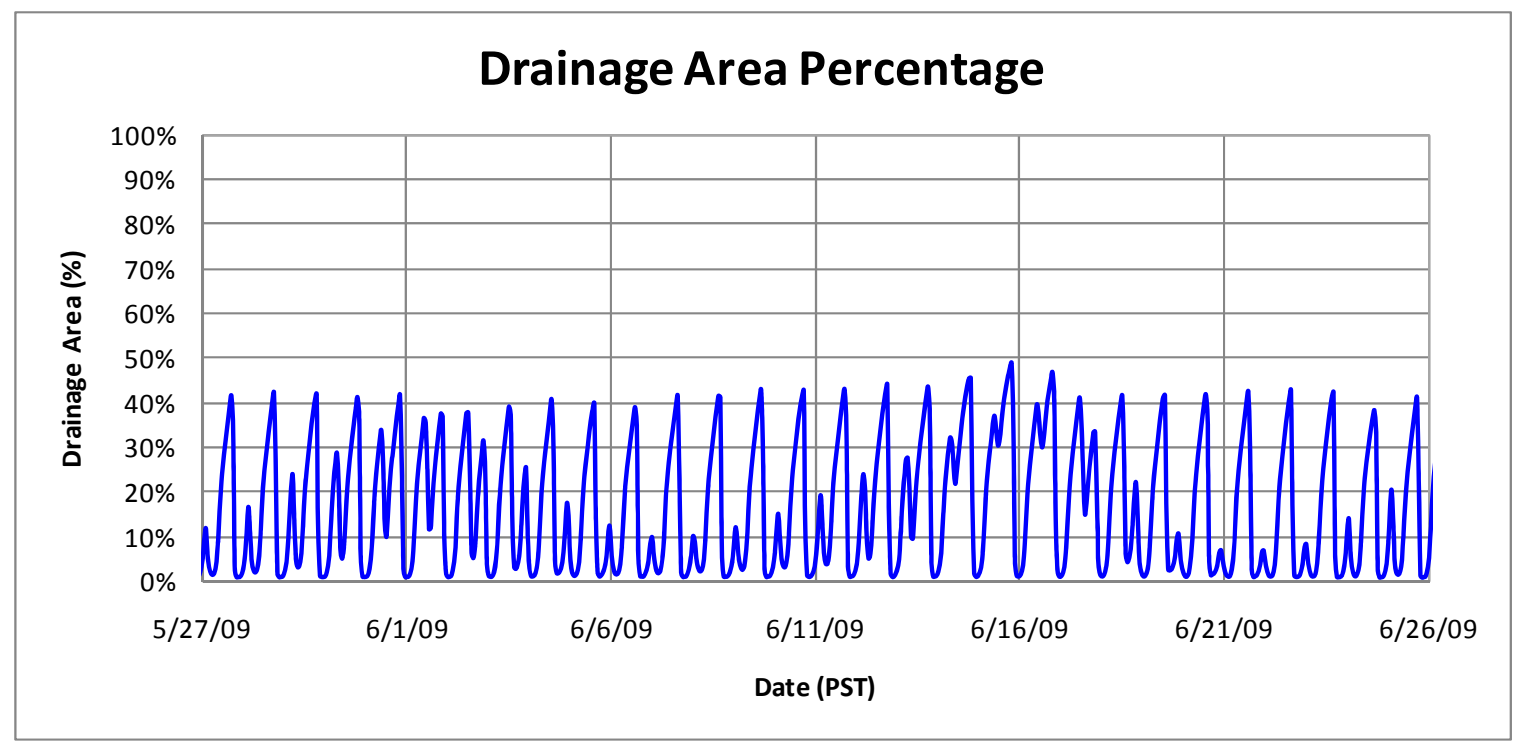

3.4. Time Series of Drainage (Dry) Area Percentage in the Project Site Under Existing Conditions

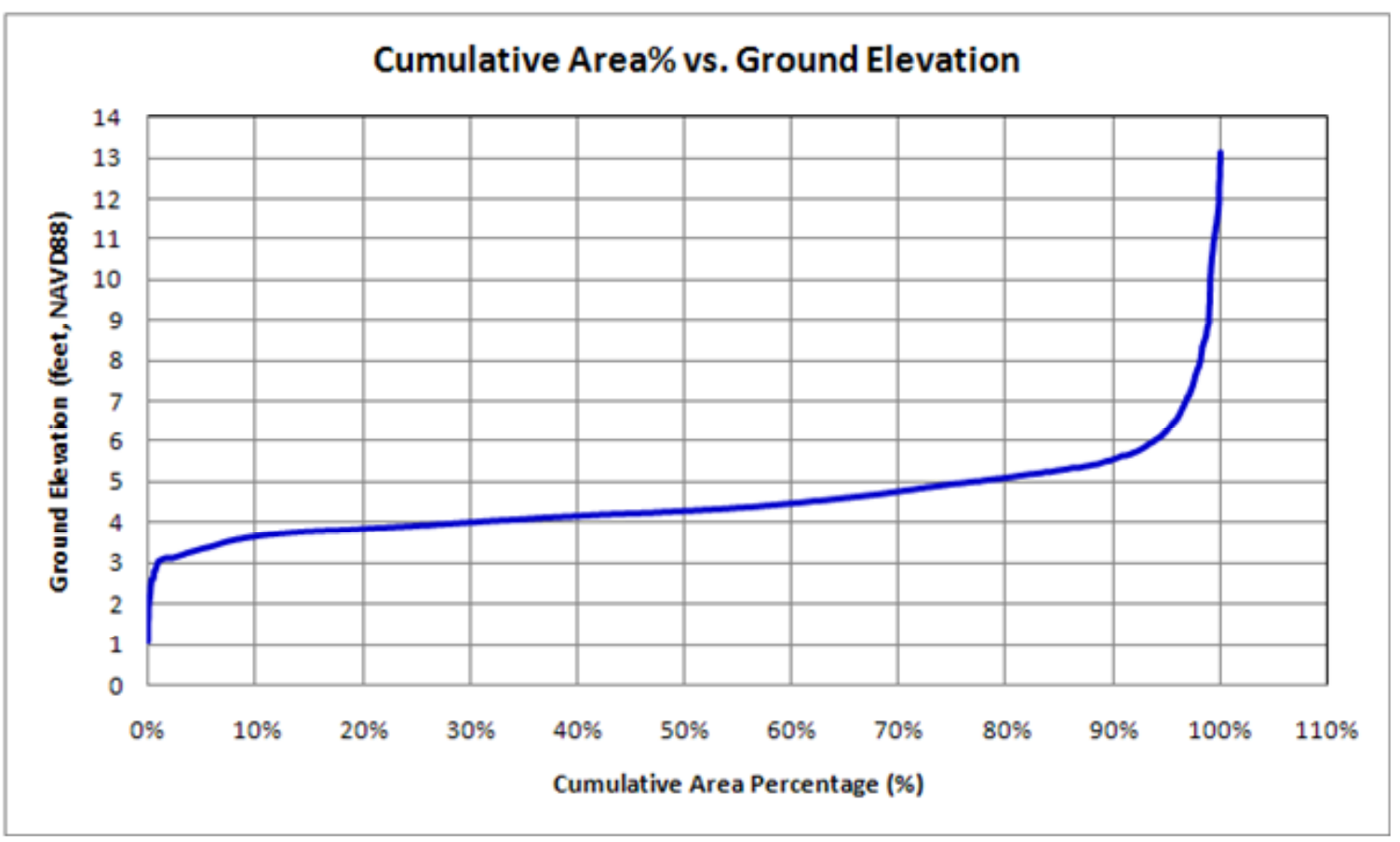

3.5. Cumulative Ground Surface Area vs. Ground Elevation in the Project Site 



\subsection{Model Accuracy and Uncertainty Analysis}

To assess the accuracy of model validation quantitatively, a model skill assessment, which generally consists of a matrix of error statistics, is conducted. In this study, the following error statistics were calculated based on model results and observed data:

- Mean Error (ME), which is defined by:

$$
M E=\frac{1}{N} \sum_{i=1}^{N}\left(\eta_{i}^{m}-\eta_{i}^{o}\right)
$$

where $\mathrm{N}$ is the total data points of field observations; $\eta_{i}^{m}$ is the modeled water level, and $\eta_{i}^{o}$ is the observed water level.

- Mean Absolute Error (MAE), which is defined by:

$$
M A E=\frac{1}{N} \sum_{i=1}^{N}\left|\eta_{i}^{m}-\eta_{i}^{o}\right|
$$

- Root Mean Square Error (RMSE), which is defined by:

$$
R M S E=\sqrt{\frac{1}{N} \sum_{i=1}^{N}\left(\eta_{i}^{m}-\eta_{i}^{o}\right)^{2}}
$$

- Relative Error (RE), which is defined by:

$$
R E=100 \% \times \frac{\sum_{i=1}^{N}\left(\eta_{i}^{m}-\eta_{i}^{o}\right)^{2}}{\sum_{i=1}^{N}\left(\left(\eta_{i}^{m}-\overline{\eta^{o}}\right)^{2}+\left(\eta_{i}^{o}-\overline{\eta^{o}}\right)^{2}\right)}
$$

where $\overline{\eta^{o}}=\frac{1}{N} \sum_{i=1}^{N} \eta_{i}^{o}$ is the observed mean water level.

Error statistics were calculated for all observed stations HOBO-1 to HOBO-5. The station-average error statistics are provided in Table 4.1. Overall, the model validation errors for water level are very good. All error-statistic values are within $10 \%$ of the tidal range $(\sim 5 \mathrm{ft})$ in the project site. The negative mean error indicates the model under-predicted the water level. It is important to know that the errors in model validation also contained the errors that propagated from the open boundary conditions where predicted water levels were specified using XTide program.

Table 4.1. Station-Average, Water-Level Error Statistics for Model Validation

\begin{tabular}{cc}
\hline Error & Value (feet) \\
\hline Mean Error (ME) & -0.29 \\
Mean Absolute Error (MAE) & 0.38 \\
Root Mean Square Error (RMSE) & 0.45 \\
\hline Relative Error (RE) (\%) & $2.46 \%$ \\
\hline
\end{tabular}


Because the drainage calculation is based on the model results of predicted water surface elevations, it is expected that there would be errors in the drainage calculation. However, it is difficult to quantify the errors in drainage calculation because there are no drainage/inundation data that may be used for model validation. Thus, a methodology was introduced to assess the uncertainty of drainage calculation, which is defined through the following steps.

1. Define wetted surface area $S_{i}^{w}$ for element $i$ in the entire project site at any given time, $t$, using wetting and drying criterion:

$$
S_{i}^{w}(t)= \begin{cases}S_{i} & \eta_{i}^{m}(t)>\eta_{g}+0.05 \\ 0 & \eta_{i}^{m}(t) \leq \eta_{g}+0.05\end{cases}
$$

where $\eta_{g}$ is the ground elevation. The criterion for an element becoming dry is $0.05 \mathrm{~m}$.

2. Calculate total dry (drainage) area $A^{d}$ in the project site:

$$
A^{d}(t)=A^{t}-\sum_{i}^{M} S_{i}^{w}(t)
$$

where $A^{t}$ is the total area, and $M$ is the total number of elements in the project site.

3. Define the upper-bound and lower-bound uncertainties for predicted water surface elevations using the largest error in the water level prediction, which is the RMSE:

$$
\eta_{u p}^{m}(t)=\eta^{m}(t)+R M S E \quad \text { and } \quad \eta_{l o}^{m}(t)=\eta^{m}(t)-R M S E
$$

From Table 4.1, the RMSE for the water-level prediction is $0.45 \mathrm{ft}$.

4. Apply $\eta_{u p}^{m}(t)$ and $\eta_{l o}^{m}(t)$ to Step 1 and 2 to obtain the upper bound and lower bound of the predicted total drainage area, $A_{u p}^{d}(t)$ and $A_{l o}^{d}(t)$

The time series of the drainage area percentage and its upper and lower bounds (i.e., multiplying $A^{d}(t), A_{u p}^{d}(t)$ and $A_{l o}^{d}(t)$ by $\left.100 / A^{t}\right)$ are shown in 4.1. It can be seen that the uncertainty for the drainage area prediction is generally within the range of $5 \%$ most of the time. The average uncertainty range (Upper Bound-Lower Bound) over the entire simulation period is 3.7\%. 


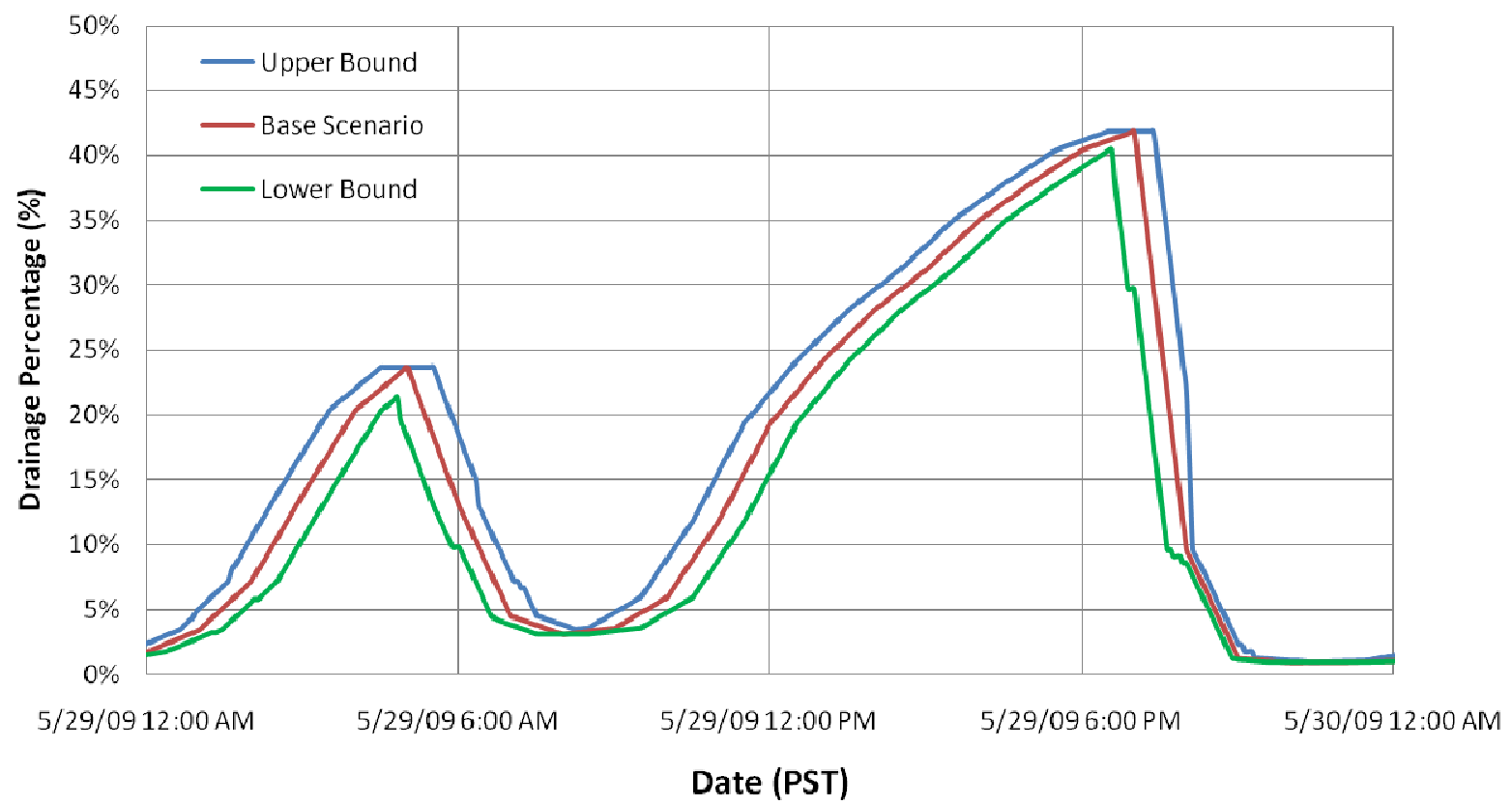

4.1. Uncertainty Range of Predicted Drainage Area Percentage 



\subsection{Model Application to Bridge Removal Scenarios}

Once the model was validated with observed data, it was applied to simulate the new restoration scenarios and evaluate the drainage efficiency in the project site. The following four bridge-removal scenarios were simulated:

1. Removal of the north bridge

2. Removal of the north and south bridge

3. Removal of the south and central bridge

4. Removal of all three bridges.

The model grid was modified in each bridge-removal scenario to represent the new restoration conditions. The bridge removal project includes removing the existing bridge, the footings and geo-grid, and the remnant levee material, as well as the earthworks in the immediate vicinity of the bridges. A clear opening along the full length of the bridge spans was created in the model for the maximum tidal drainage simulation.

\subsection{Scenario I-Removal of North Bridge}

In this scenario, the north bridge in the project site was removed. The model bathymetry was modified to represent the complete removal of the entire bridge span. The bathymetry right near the bridge opening was smoothed to allow full tidal exchanges. The new ground elevation at the bridge removal location was $2.15 \mathrm{ft}$ NAVD88. A comparison of model grids before and after bridge removal is shown in 5.1 .

Compared to existing conditions, the drainage in the project site was improved under the north bridge removal condition (5.2). The maximum drainage percentage during low tides increased from $40 \%$ under existing conditions to 50\% under north bridge removal conditions with respect to the total area of the project site. A time series of water surface elevation under north bridge removal conditions is also compared to the existing conditions at Station N1 near the north bridge. 5.3 shows that the water level under north bridge removal conditions drops faster during ebb tides and lower at low tides than that in the existing conditions.

The distribution of the maximum drainage area under north bridge removal conditions was also compared to existing conditions (5.4) at 6 PM PST, 5/28/2009, during low tide. It can be seen that the drainage area in the northern part of the project site with north bridge removal increases significantly compared to existing conditions. However, the drainage area in the central and southern parts of the project site remains almost the same.

Comparisons of depth-average velocity distribution in the enduring ebb and flood tides before and after north bridge removal are shown in 5.5a, b, c. In general, under north bridge removal conditions, the ebbing velocities near the north bridge increase, and the flooding velocities are similar to the existing conditions, which is consistent with the changes in the drainage area and the water level shown in 5.2 and 5.3 . 


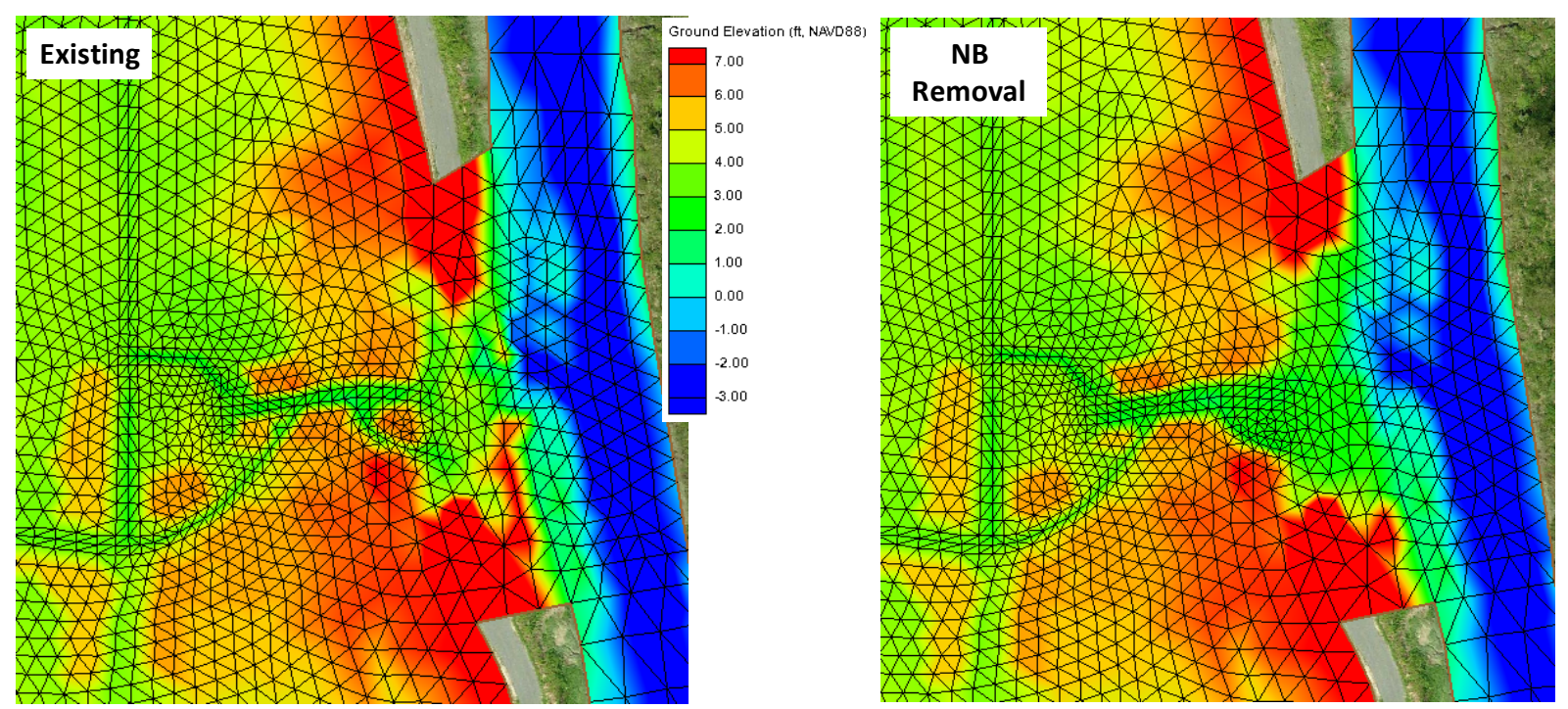

5.1. Comparison of Model Grids near North Bridge Area

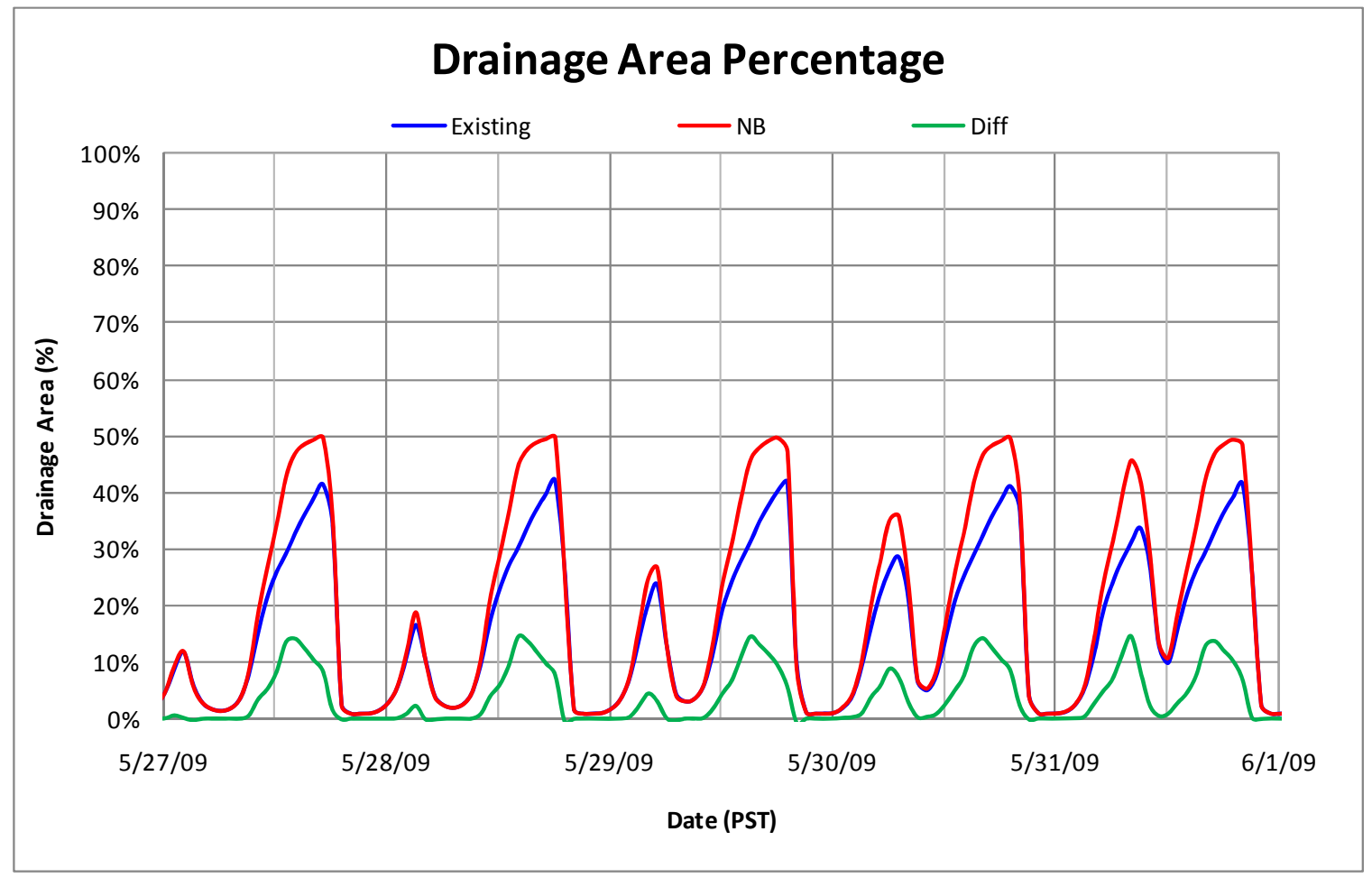

5.2. Drainage Area Percentage Under North Bridge Removal Conditions 


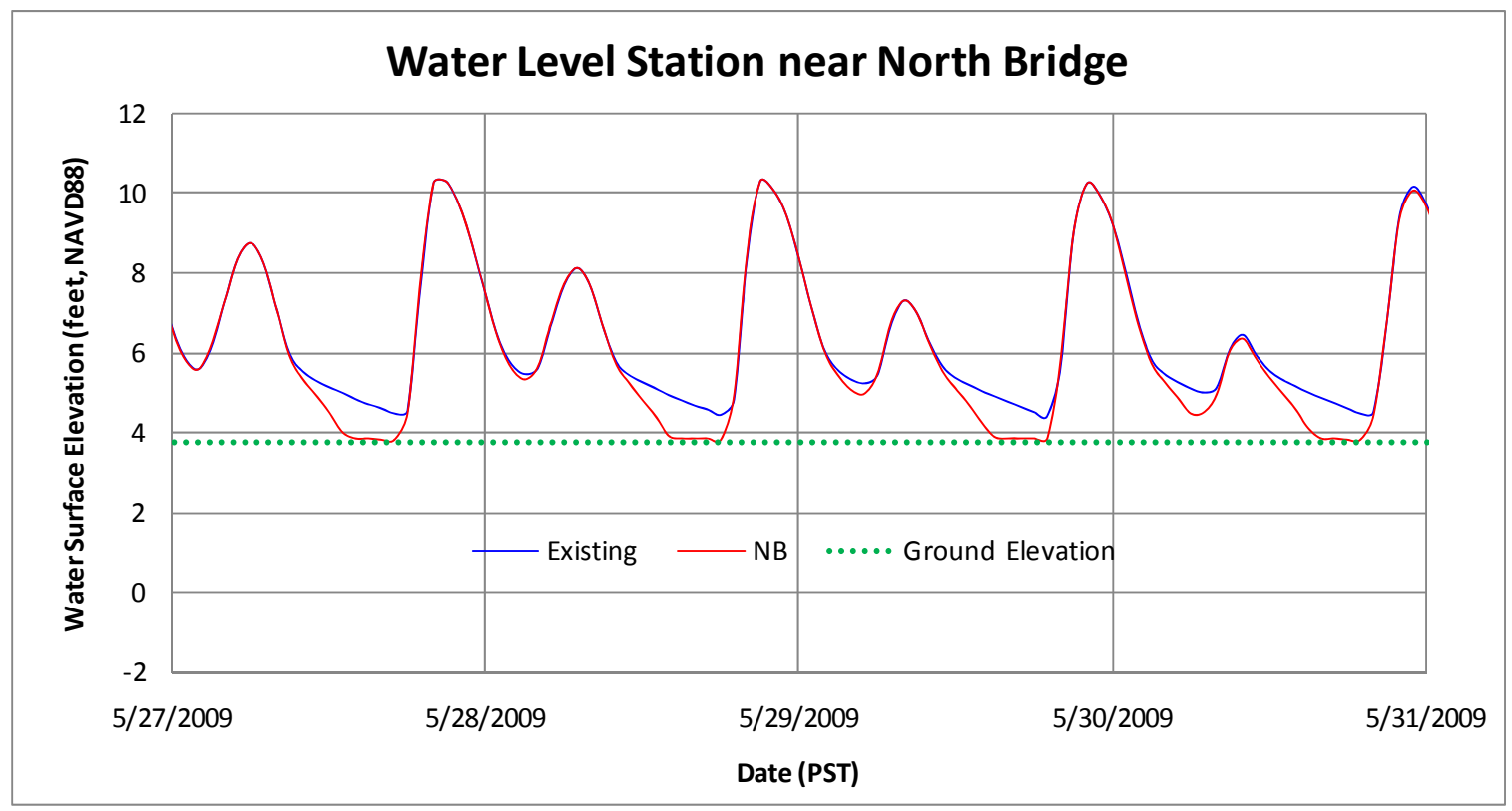

5.3. Water Level Comparisons between Existing and North Bridge Removal Conditions at Station N1
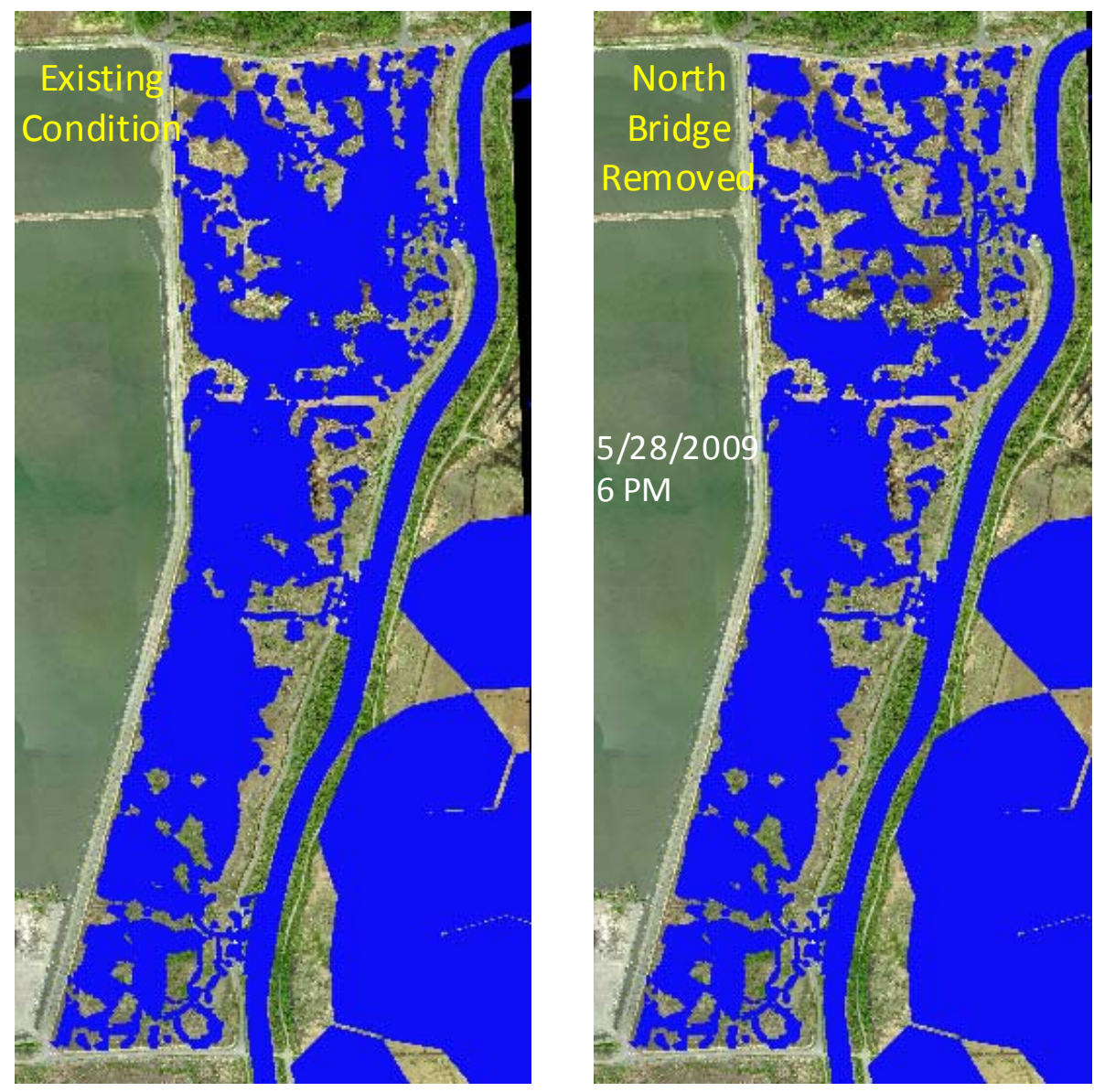

5.4. Comparison of the Maximum Drainage Areas Under Existing and North Bridge Removal Conditions 


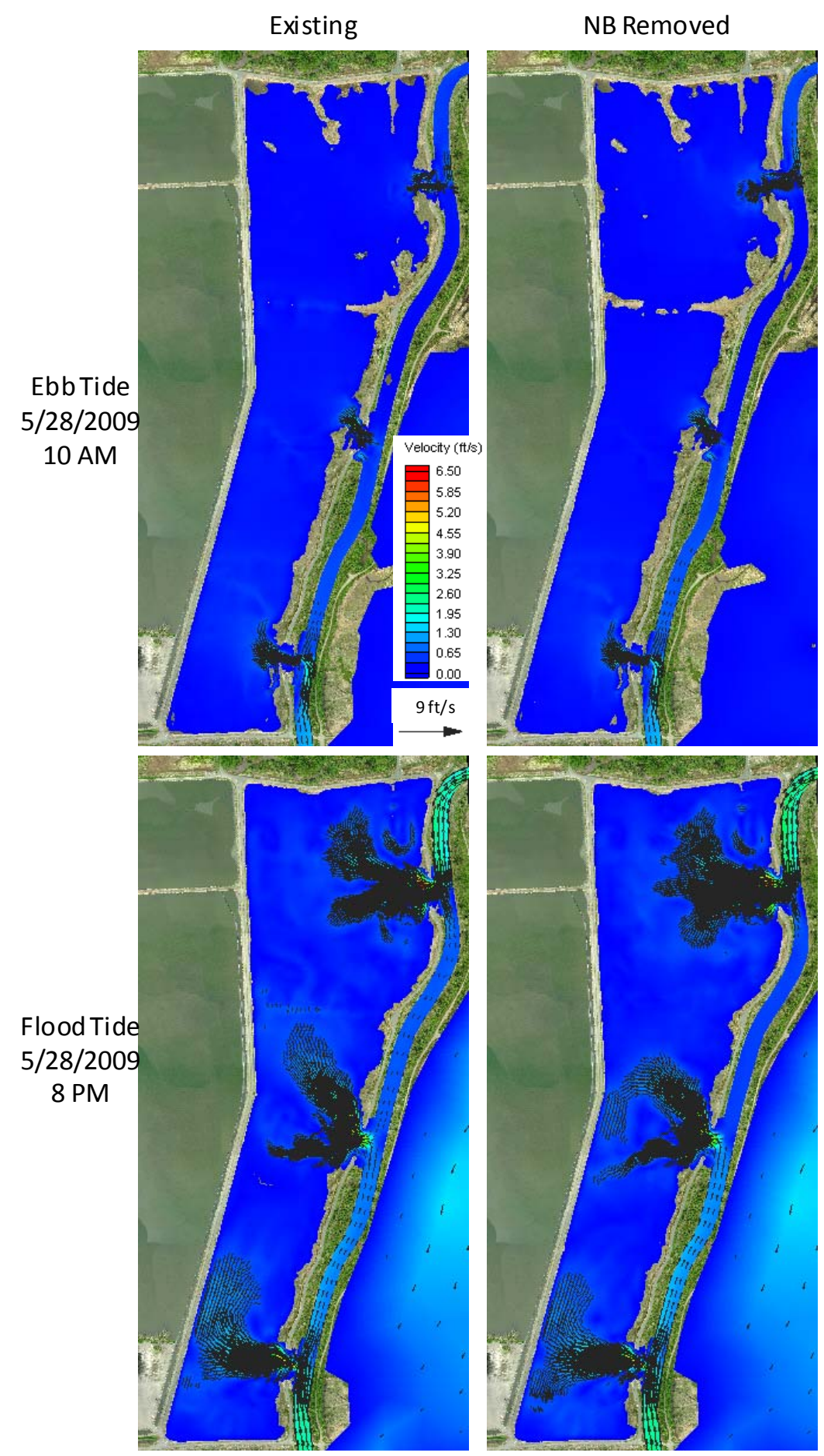

5.5a. Comparisons of Depth-average Velocities at Ebb and Flood Tides Under Existing and North Bridge Removal Conditions 


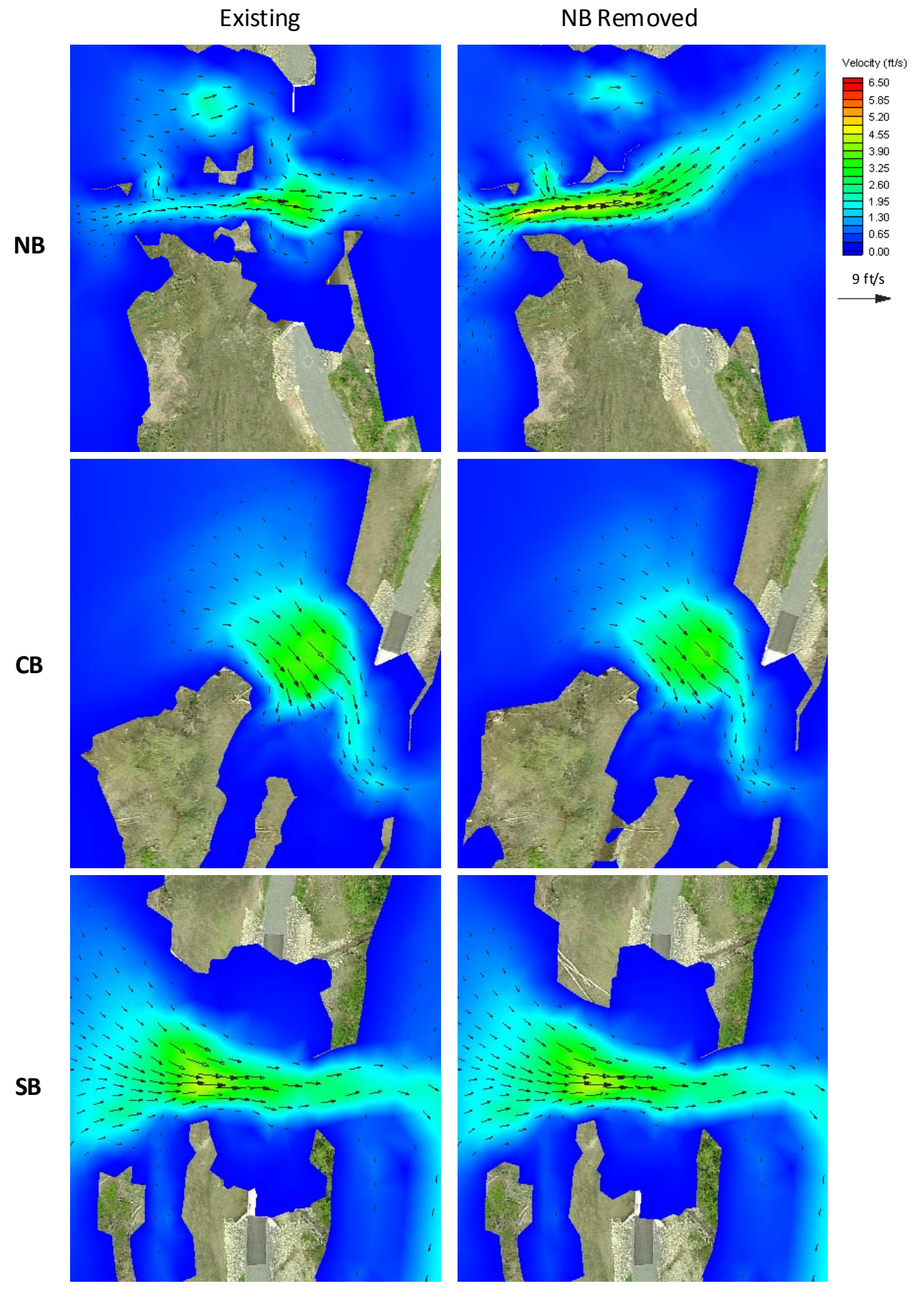

5.5b. Close-up Snapshots of Depth-average Velocities at Ebb Tides Near Bridge Locations Under Existing and North Bridge Removal Conditions 

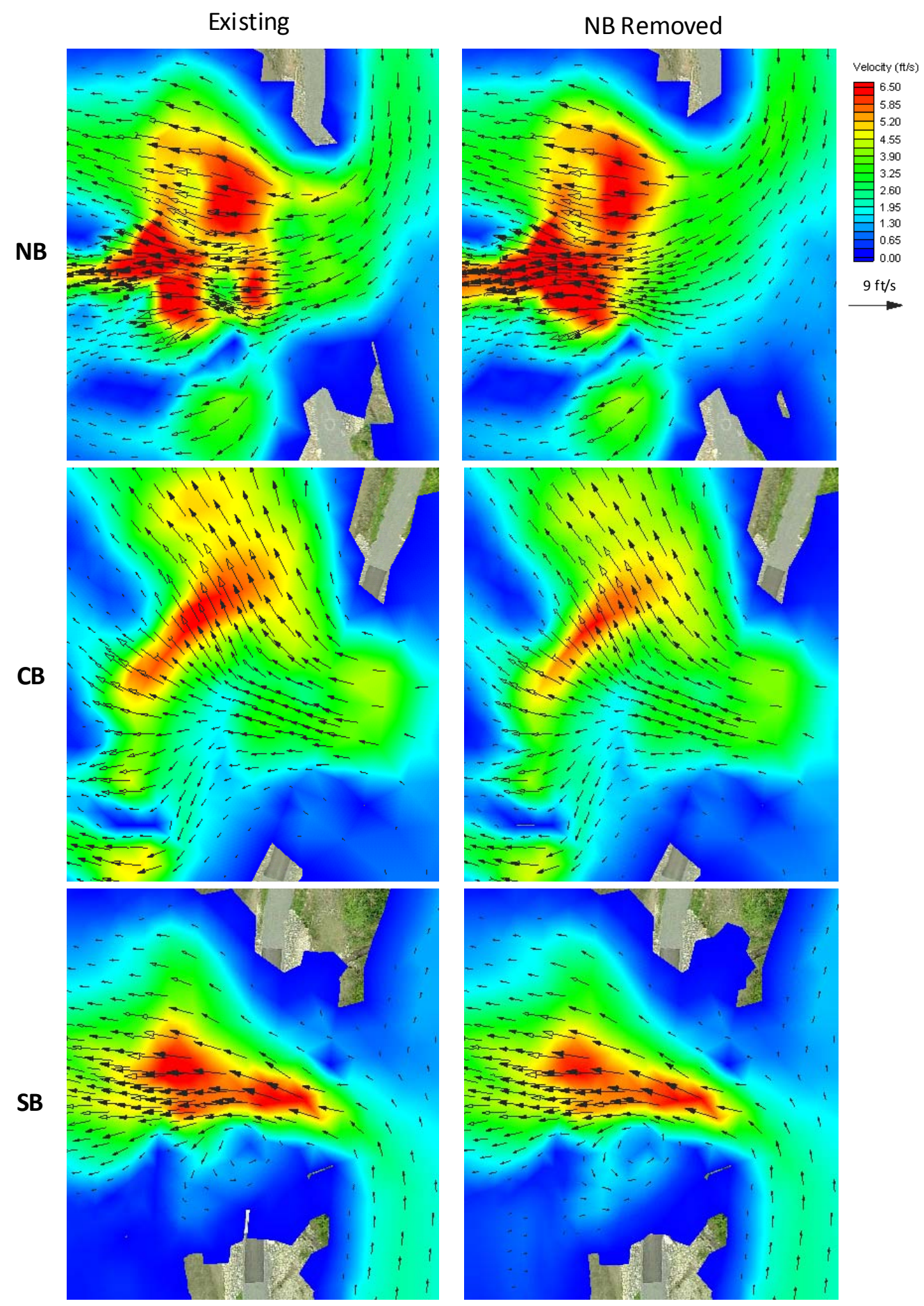

5.5c. Close-up snapshots of Depth-average Velocities at Flood Tides near Bridge Locations Under Existing and North Bridge Removal Conditions

\subsection{Scenario II-Removal of North and South Bridges}

In this scenario, both the north and the south bridges were removed from the project site. The model grid in the north bridge area remained the same as Scenario I. The new ground elevation at the south 
bridge removal location was $2.7 \mathrm{ft}$ NAVD88. The modification of the model grid near the south bridge is shown in 5.6.

The drainage area percentage with respect to the total area of the project site was calculated for this scenario and compared to existing conditions. 5.7 shows that model results under the north and south bridge removal conditions are very similar to the model results under north bridge removal conditions (5.2). Therefore, removing the south bridge provided little improvement of drainage in the project site.

Comparisons of water levels, drainage areas, and velocities are not presented for this scenario because they are similar to those under north bridge removal conditions.
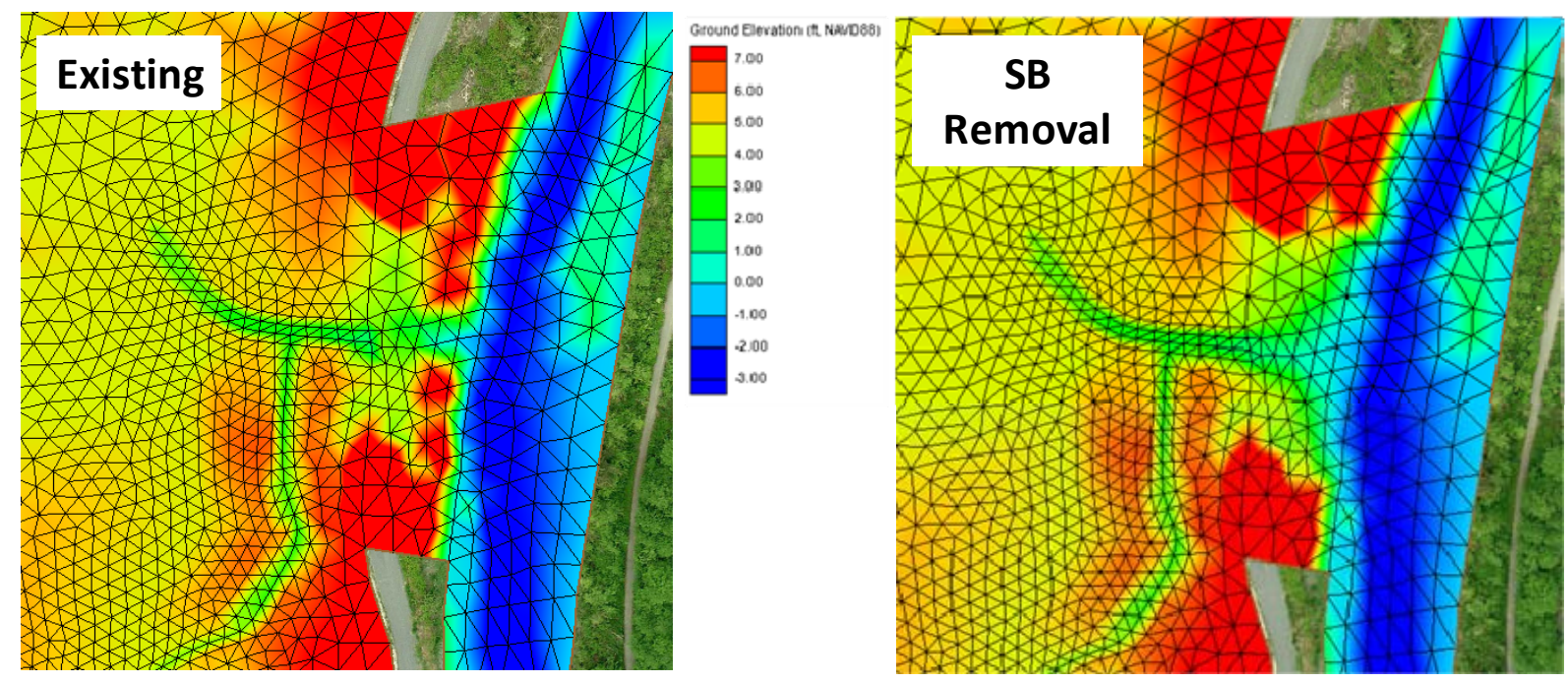

5.6. Comparison of Model Grids near South Bridge Area 


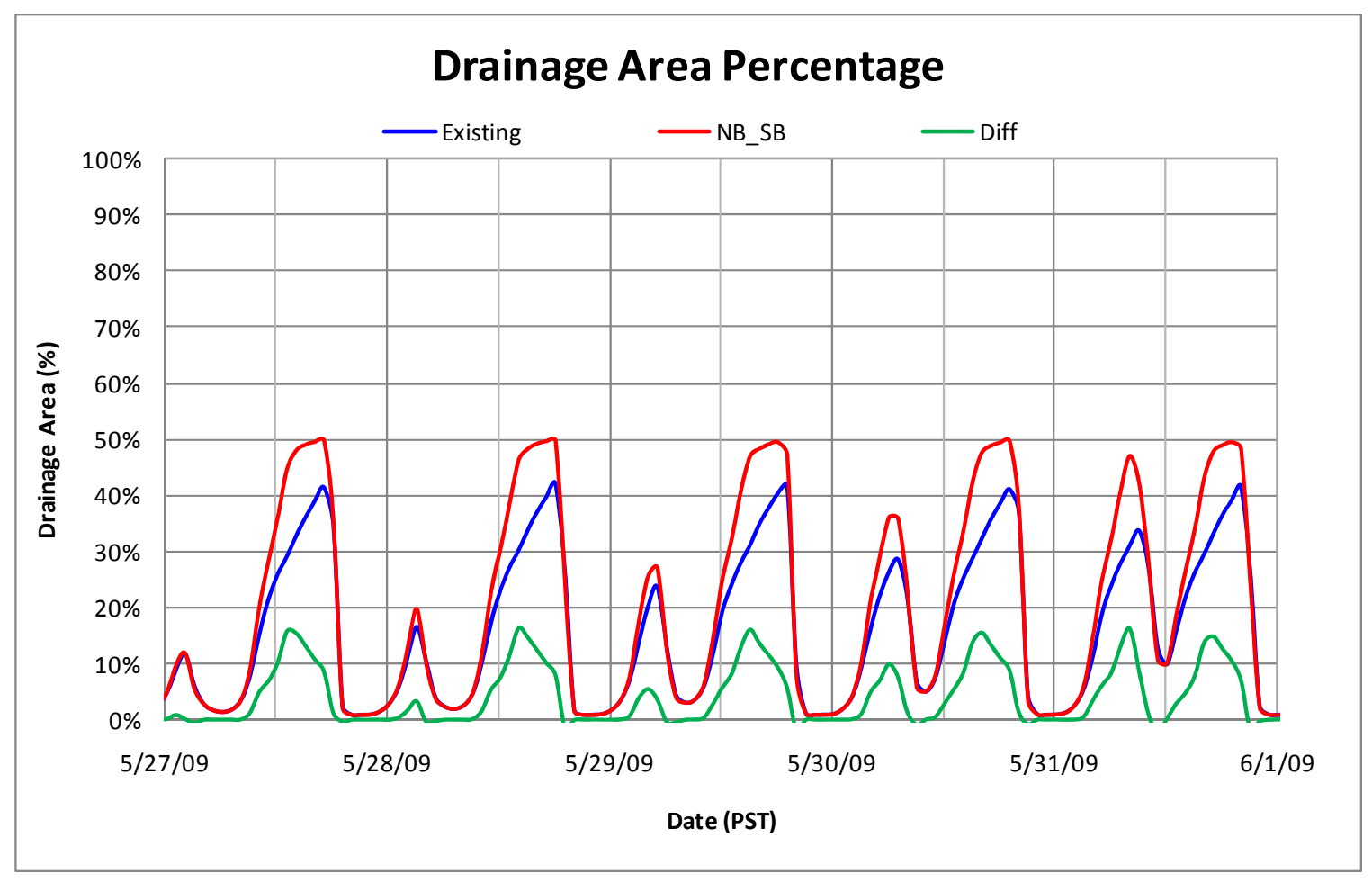

5.7. Drainage Area Percentage under North and South Bridge Removal Conditions

\subsection{Scenario III-Removal of South and Central Bridges}

In this scenario, both central and south bridges were removed from the project site. The model grid in the south bridge area remained the same as Scenario II (5.6). The new ground elevation at the central bridge removal location was $2.4 \mathrm{ft}$ NAVD88. The modification of the model grid near the central bridge is shown in 5.8 .

The drainage area percentage with respect to the total area of the project site was calculated for this scenario and compared to existing conditions. 5.9 showed that model results under the central and south bridge removal conditions are very similar to the model results under existing conditions. Therefore, removing the central and south bridges basically did not improve the drainage in the project site.

Comparisons of water levels, drainage areas, and velocities are not presented for this scenario because they are similar to those under existing conditions. 

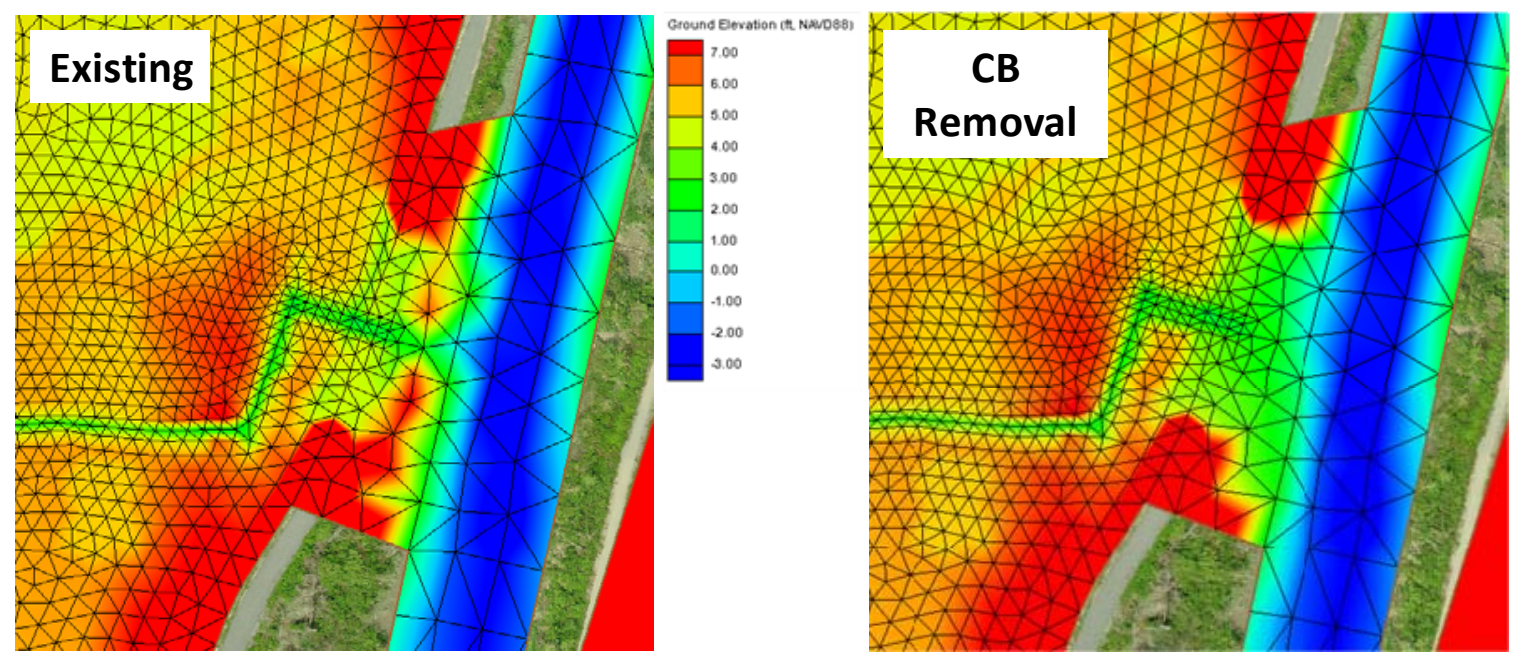

5.8. Comparison of Model Grids near Central Bridge Area

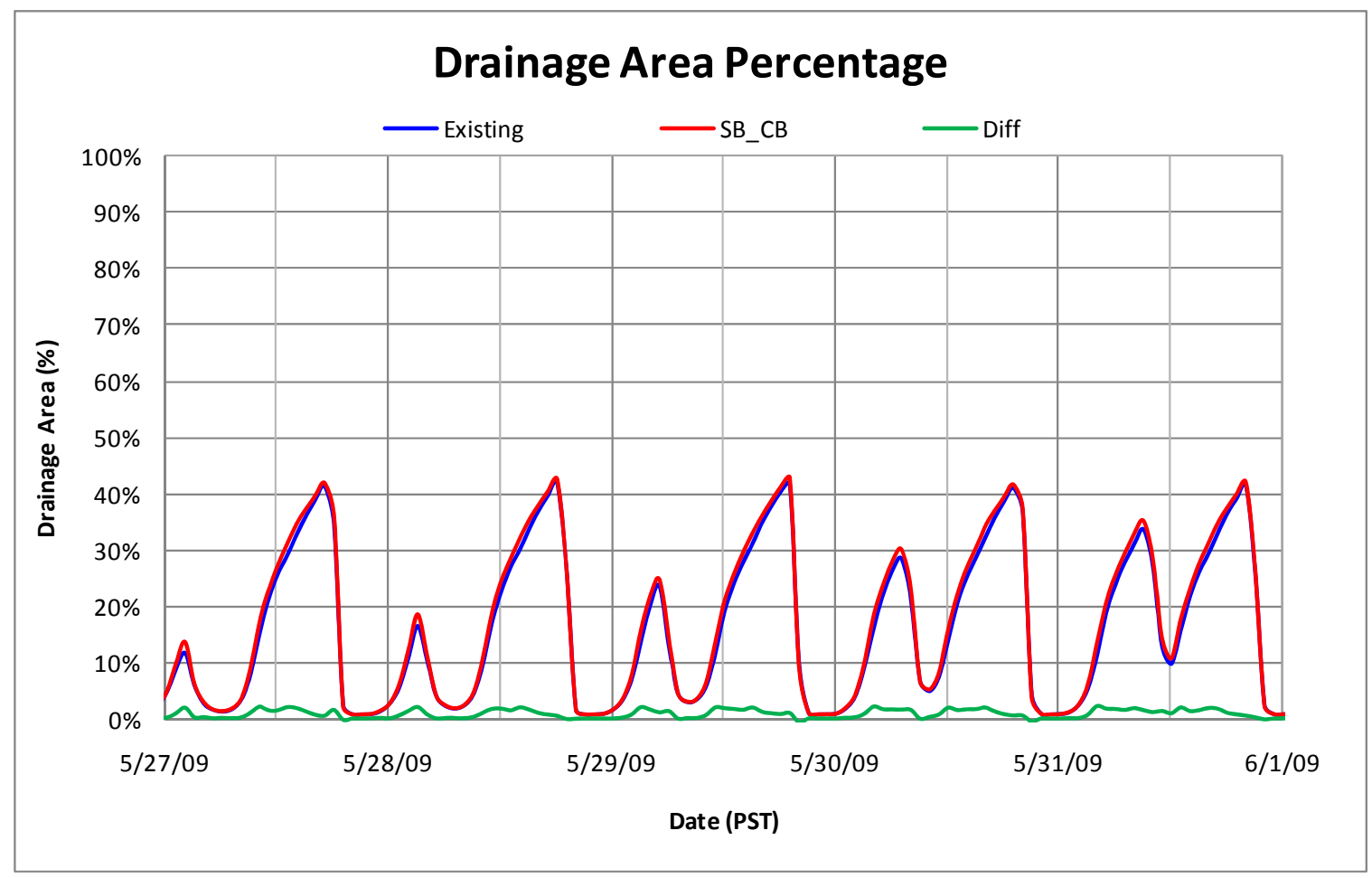

5.9. Drainage Area Percentage Under Central and South Bridge Removal Conditions

\subsection{Scenario IV-Removal of All Bridges}

In this scenario, all three bridges were removed from the project site. Modifications of the model grid near the bridges areas under this scenario are shown in 5.1, 5.6, and 5.8.

The drainage area percentage with all bridges removed was calculated and compared to existing conditions. 5.10 shows that model results with all bridges removed were still similar to the model results under the north bridge removal scenario (5.2). The drainage area percentage only increases by 2 to $3 \%$ 
during ebb tides compared to north bridge removal conditions. This result was consistent with those predicted in the central and south bridge removal scenarios (5.9).

A time series of water surface elevations under all bridge removal conditions was compared to existing and north bridge removal conditions at three stations (N1, C1 and S1) near the bridges. 5.11 shows that water levels between all bridges removed and north bridge removal conditions are almost identical. Compared to existing conditions, only water levels near the north bridge show any difference, and no improvement is observed in the central and south bridge regions.

Comparisons of drainage areas and velocities were not presented for this scenario because they are similar to those under the north bridge removal conditions.

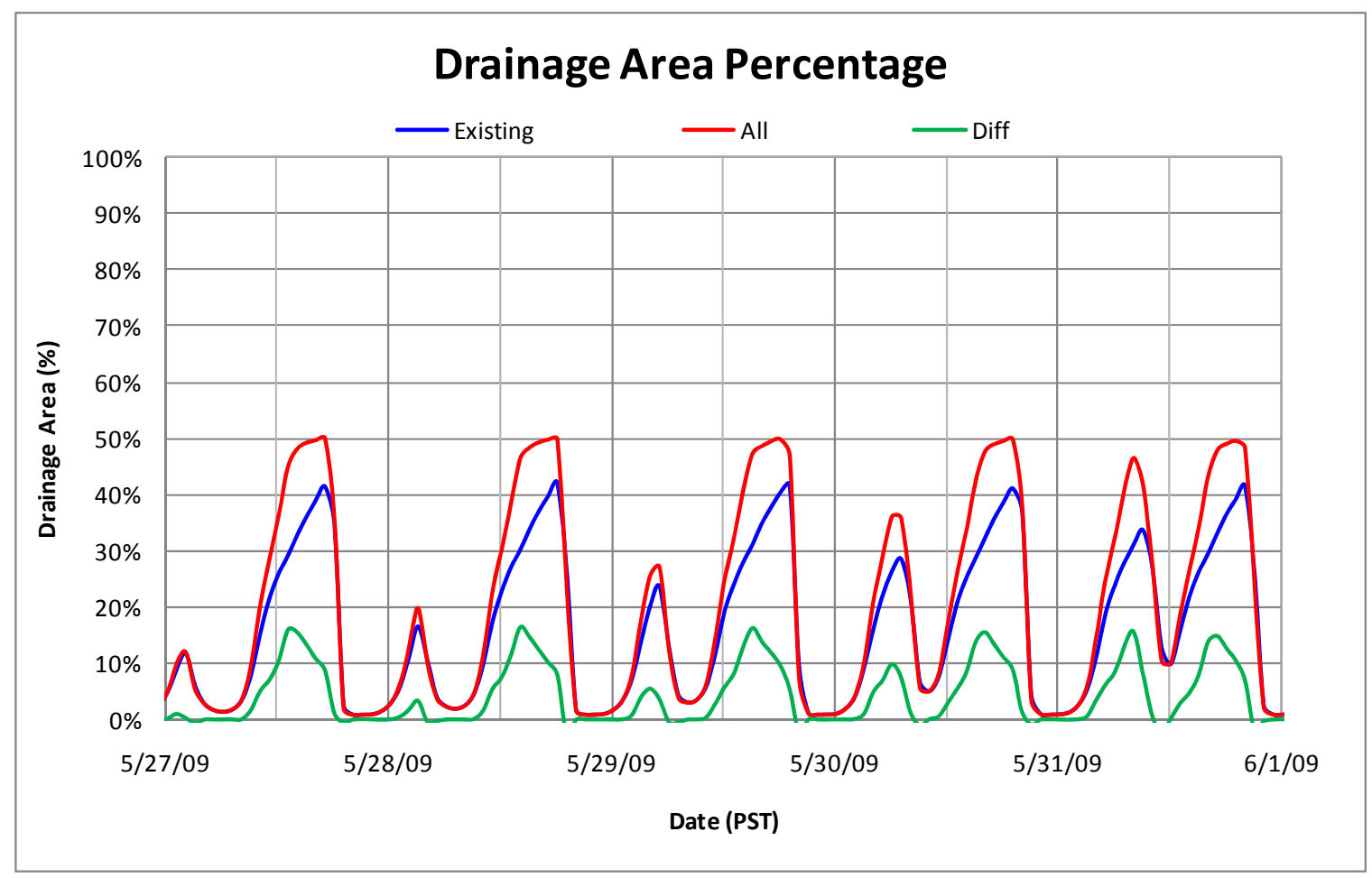

5.10. Drainage Area Percentage Under All Bridge Removal Conditions 

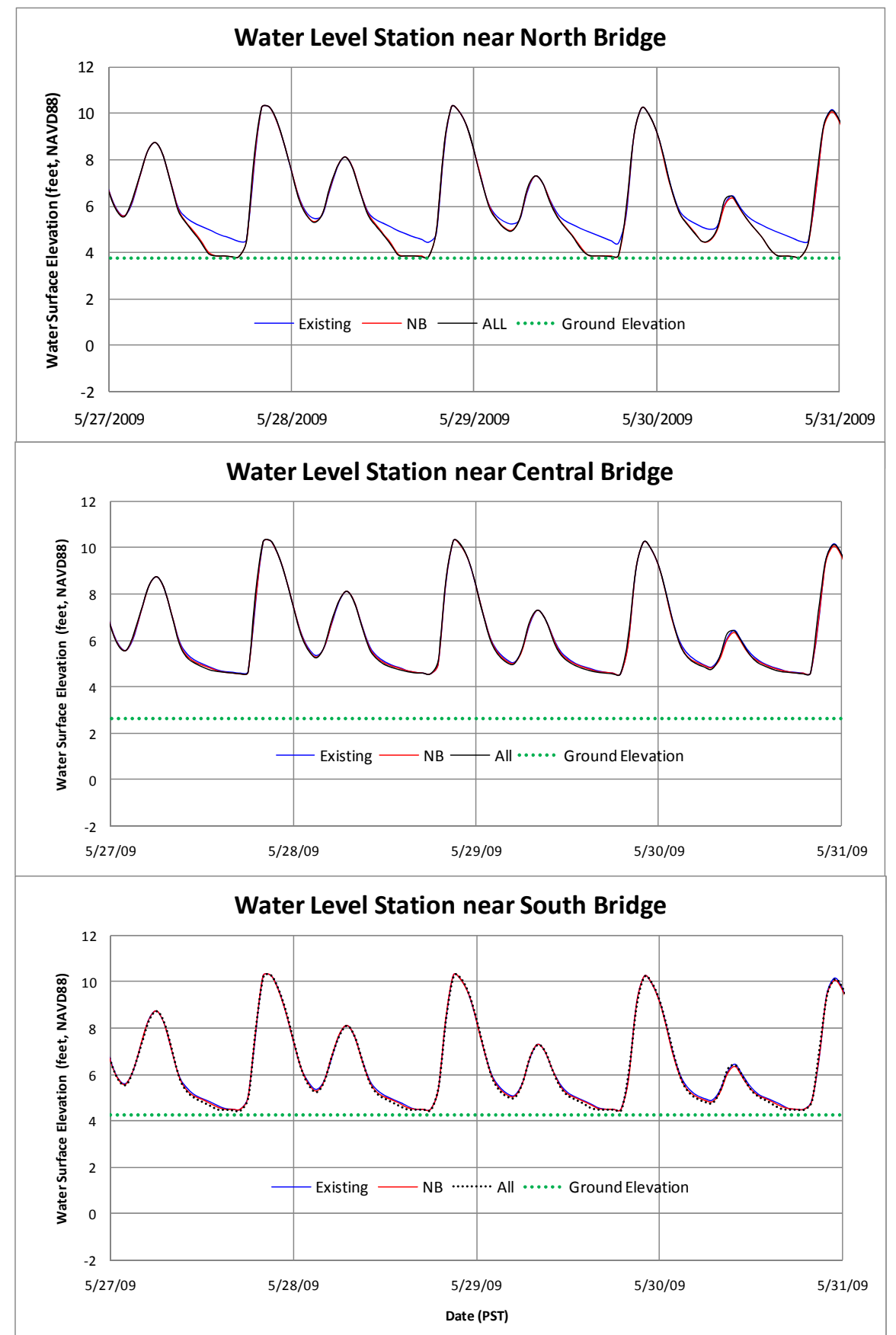

5.11. Predicted Water Levels at Station N1, C1, and S1 Under Existing, North Bridge Removal, and All Bridges Removed Conditions 



\subsection{Low Tide Channel and All Bridges Removed Scenario}

Based on the model results of bridge-removal scenarios described in Section 6, a scenario was proposed to further improve the drainage in the project site by creating low-tide channels connecting the isolated ponding areas, especially in the central region of the site, along with all bridges removed. In this scenario, a total of four low-tide channels were considered: one northern channel connecting the northern and central regions and three central channels connecting the low ponding areas to the central bridge opening (6.1). No channel was considered in the southern region near the south bridge.

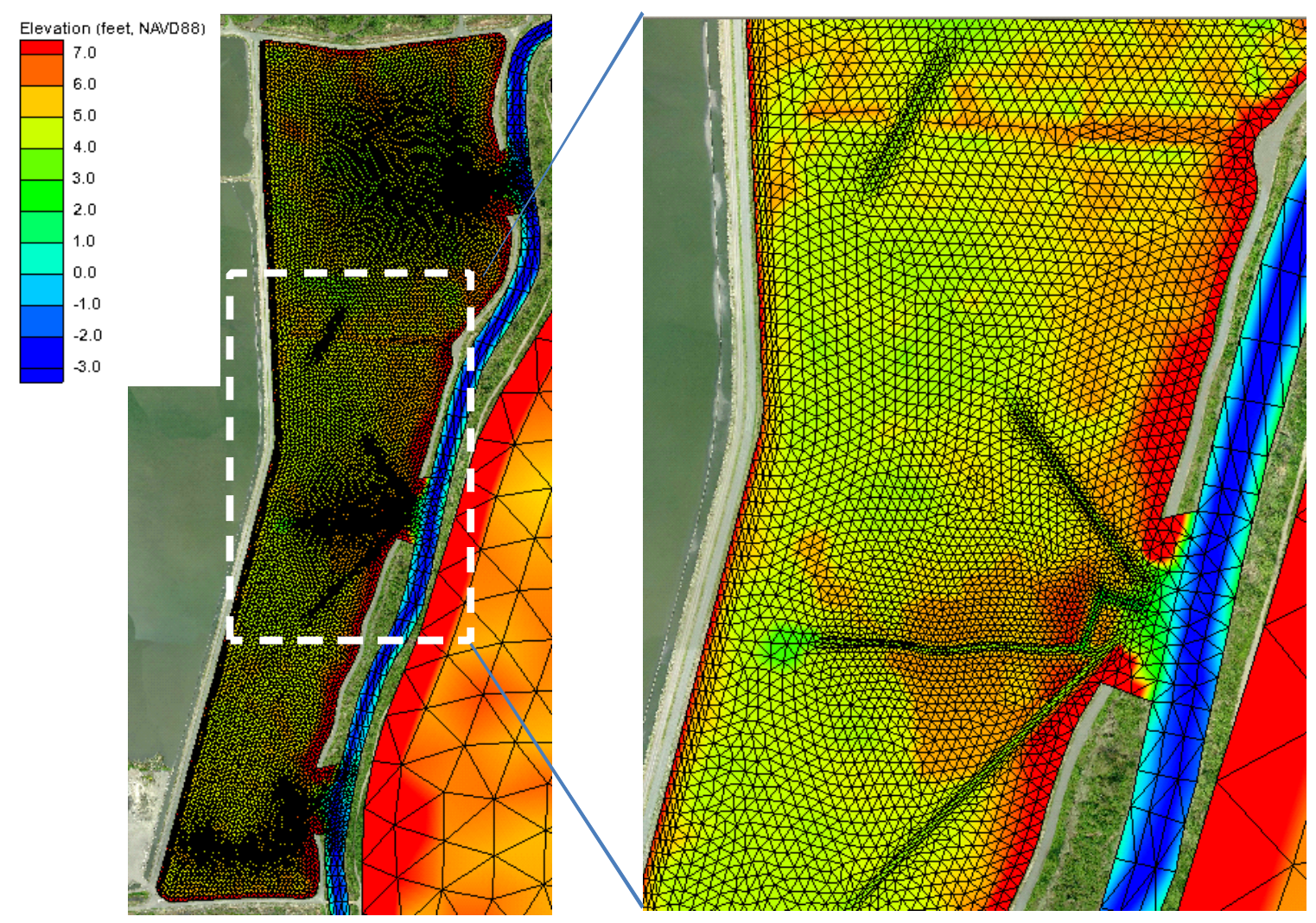

6.1. Model Grid Configuration for Low Tide Channel and All Bridges Removed Conditions

The configurations of the channels are as follows:

- 8 feet wide at the base and bottom elevation at 3.5 feet NAVD88

- Side slopes of the channels were kept as close as possible to the proposed ratio of 2:1 with consideration of the model stability

- Lengths of the channels were specified according to the following proposed values with slight modifications based on the bathymetry distributions.

- Northern channel-290 feet

- Central Bridge North Channel-400 feet

- Central Bridge Center Channel-330 feet

- Central Bridge South Channel-490 feet. 
Comparison of model bathymetries between all bridge removal and bridge removal+low tide channel conditions is shown in 6.2. Changes due to the presence of a low tide channel are clearly seen.

\section{Bridge Removal}

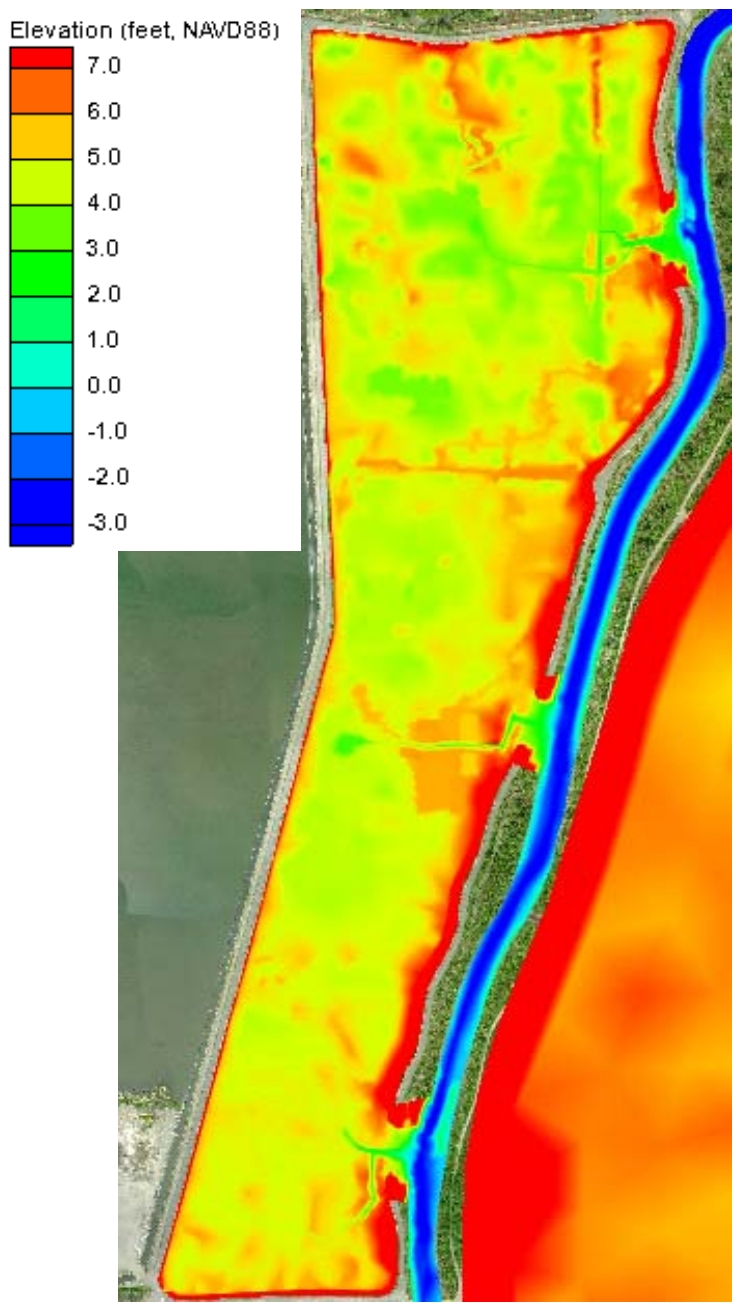

\section{Bridge Removal + Low-tide Channel}

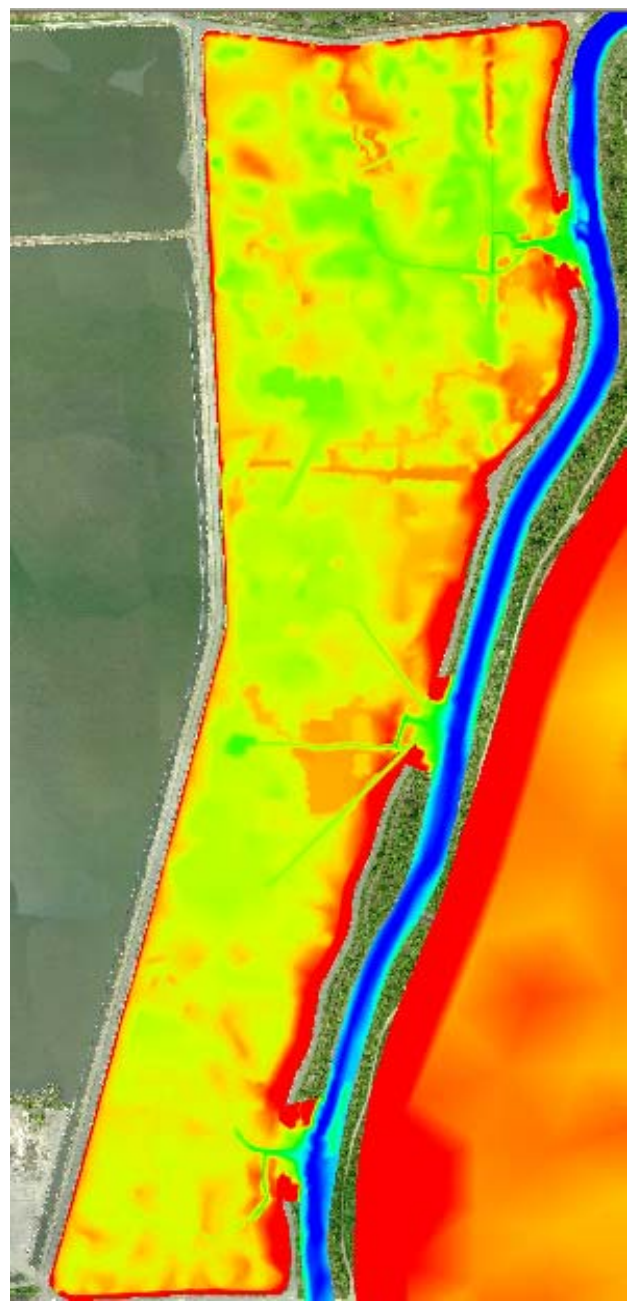

6.2. Comparison of Model Bathymetry Between Bridge Removal and Bridge Removal+Low Tide Channel Conditions

Model results indicated that the drainage area percentage under all bridges removed and low tide channel conditions improved considerably (6.3). Water in the project site drained faster under low tide channel conditions than the existing conditions, which indicated that tidal fluctuations in the project site were more in phase with tides in Union Slough. The drainage area under a low-tide channel increased by about $20 \%$ compared to existing conditions with no bridges removed (6.3).

Comparisons of water-level time series between existing and low tide channel conditions at three stations near north (N1), central (C1), and south (S1) bridges are shown in 6.4. It can be seen that under low tide channel conditions, water levels near the north and central bridges dropped further down to elevations of $3.8 \mathrm{ft}$ and $4.0 \mathrm{ft}$ during low tides, respectively. It should be noted that the bottoms of the low tide channels were specified at elevation 3.5 feet. Therefore, it is expected that the drainage speed 
would slow down when water levels fell near $3.5 \mathrm{ft} \mathrm{NAVD88.} \mathrm{Although} \mathrm{water} \mathrm{levels} \mathrm{near} \mathrm{the} \mathrm{south}$ bridge (S1) under low tide channel conditions also drained faster than the existing conditions during ebb tide, it did not drop further during low tides, and it remained at the same level as the existing conditions at and elevation of 4.5 feet. Therefore, low tide channels near the north and central bridges did not improve drainage in the southern part of the project site during low tides.

Comparing drainage areas and water depths during low tide between all bridges removed and low tide channel conditions indicates that the low tide channel scenario mainly improved the drainage in the central region (6.5a). To further demonstrate the improvement of drainage under low tide, channel conditions, the maximum drainage areas between existing and low tide channel conditions are compared in 6.5b. A visual comparison of depth-averaged horizontal 2D velocities between existing and low tide channels showed that velocities near the bridge openings increased during ebb and flood tides under low tide channel conditions $(6.6 \mathrm{a}, \mathrm{b}, \mathrm{c})$.

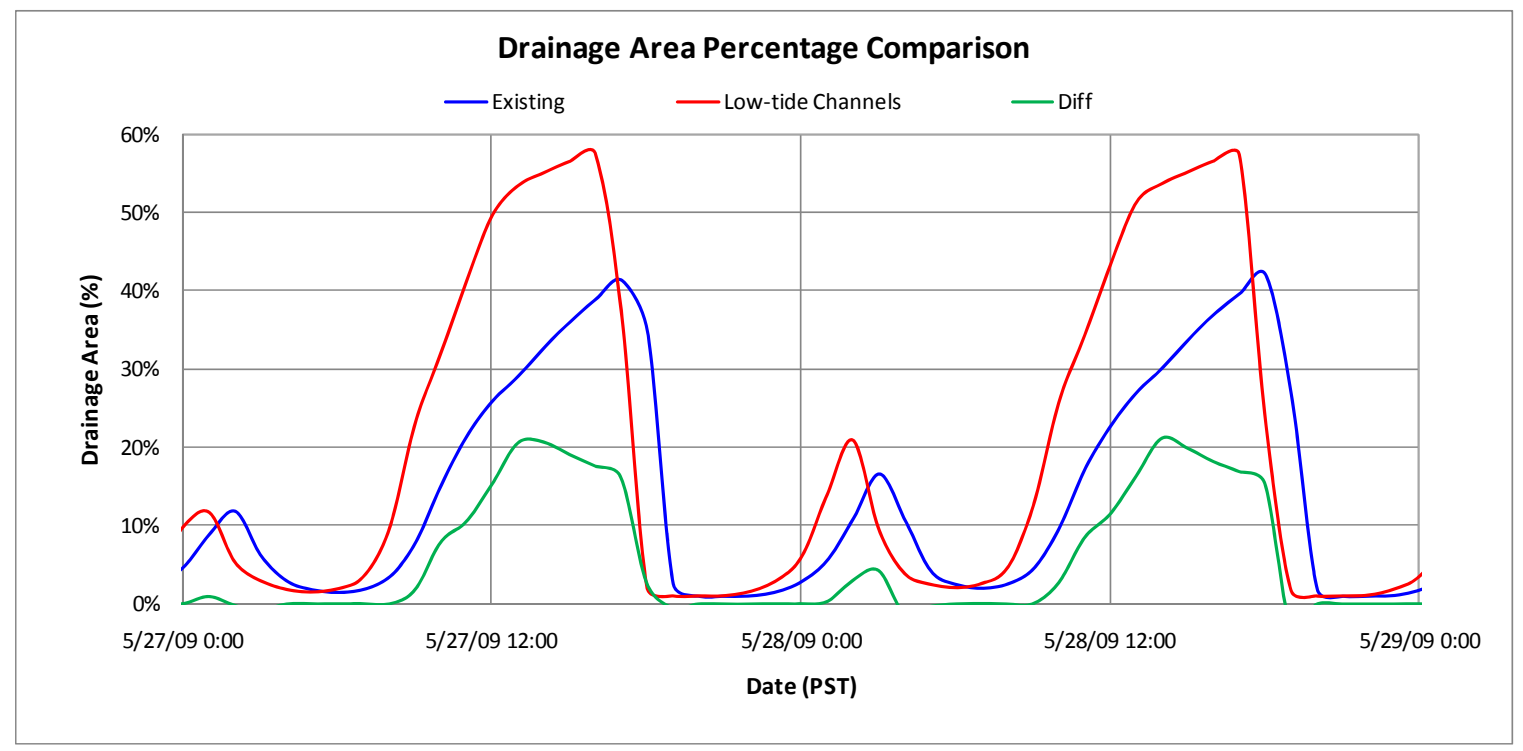

6.3. Drainage Area Percentage Under Bridge Removal+Low Tide Channel Conditions 

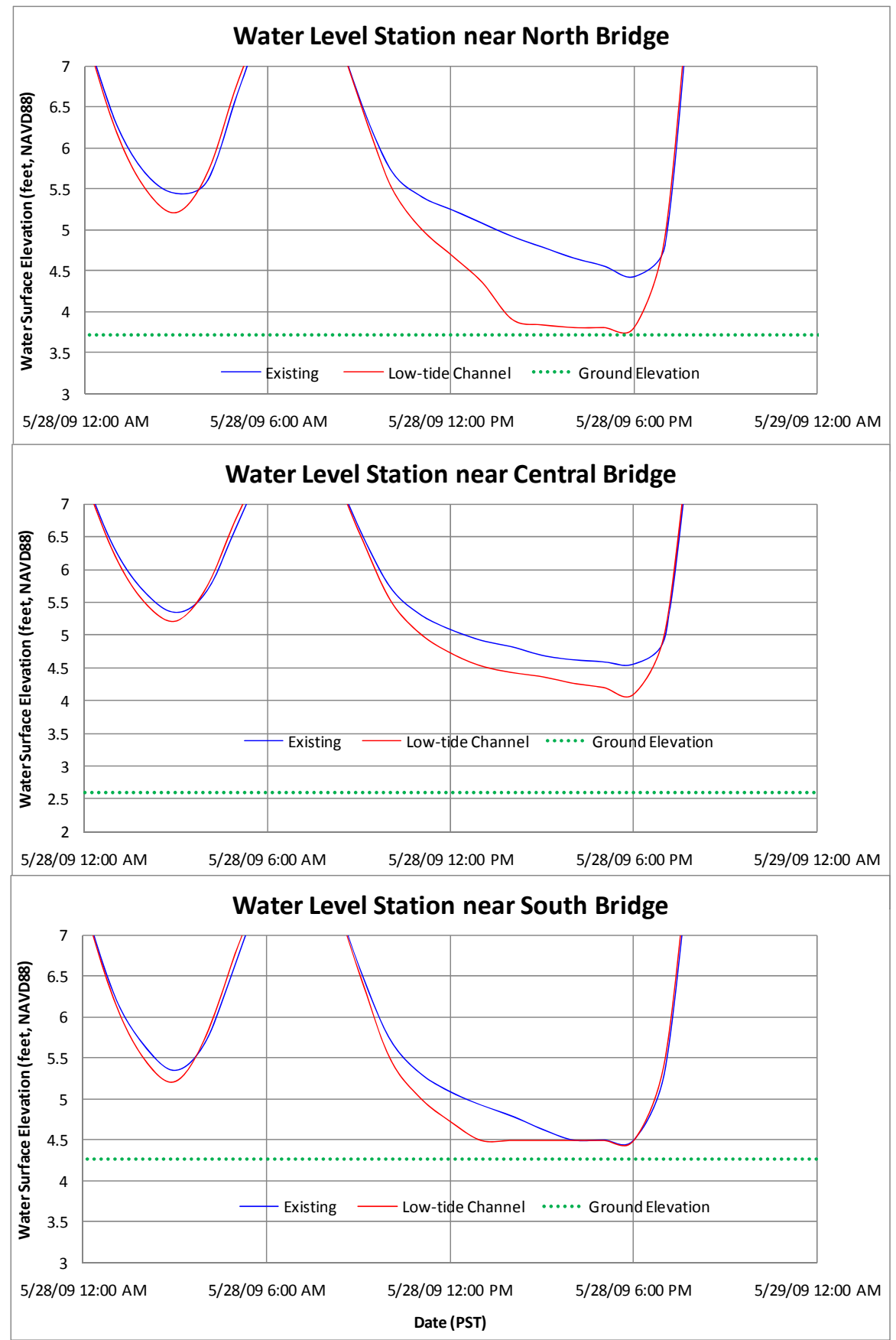

6.4. Predicted Water Levels at Stations N1, C1, and S1 under Existing and Bridge Removal+Low Tide Channel Conditions 


\section{Bridge Removal}
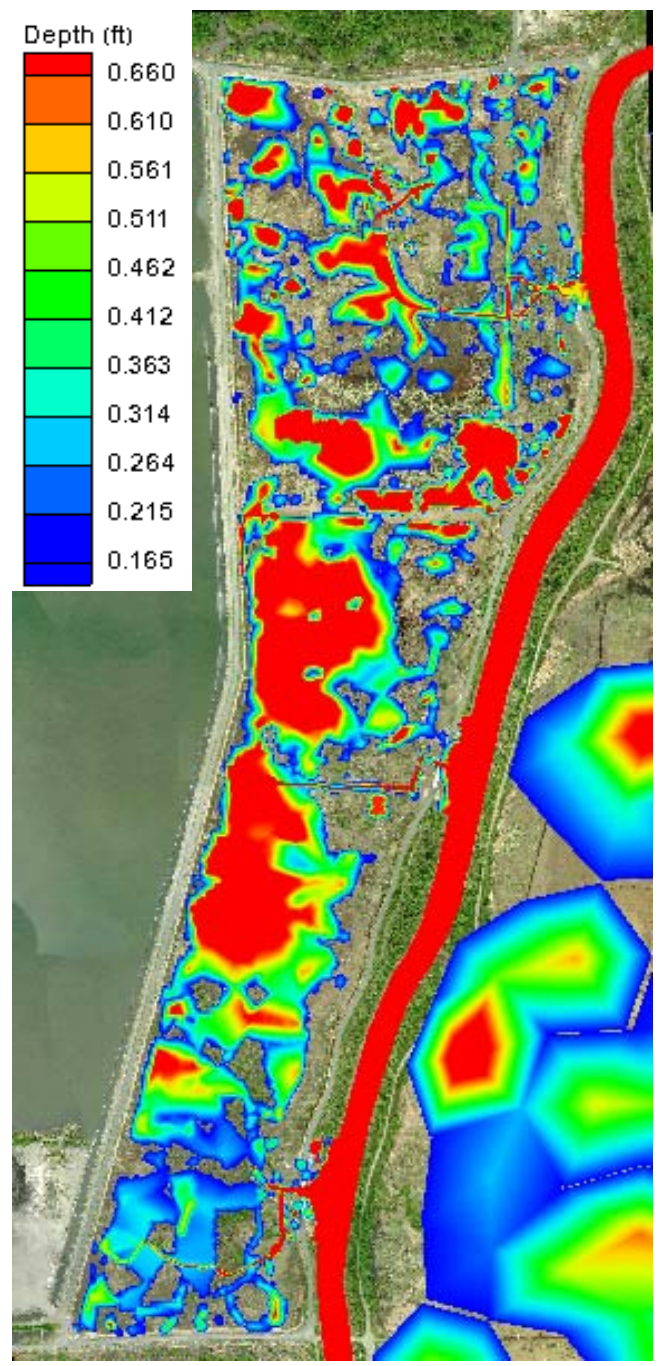

\section{Bridge Removal + Low-tide Channel}

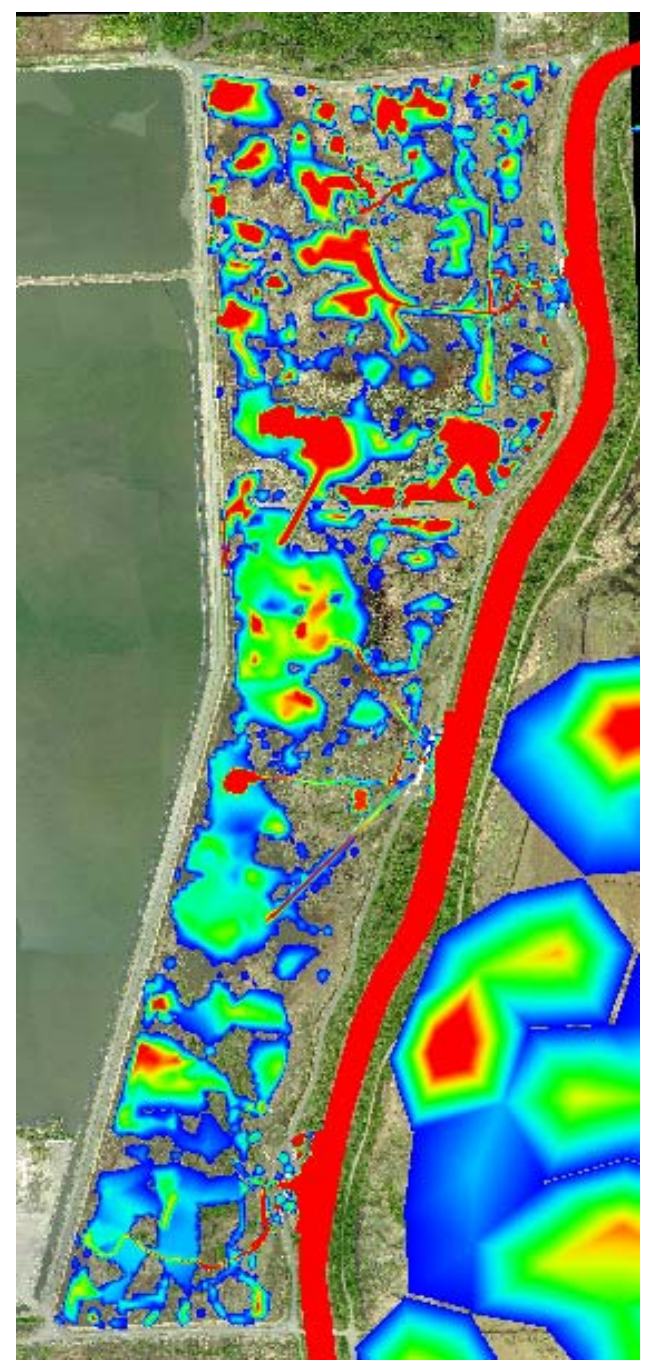

6.5a. Comparison of Drainage Areas and Water Depths Between Bridge Removal and Bridge Removal+Low Tide Channel Conditions 

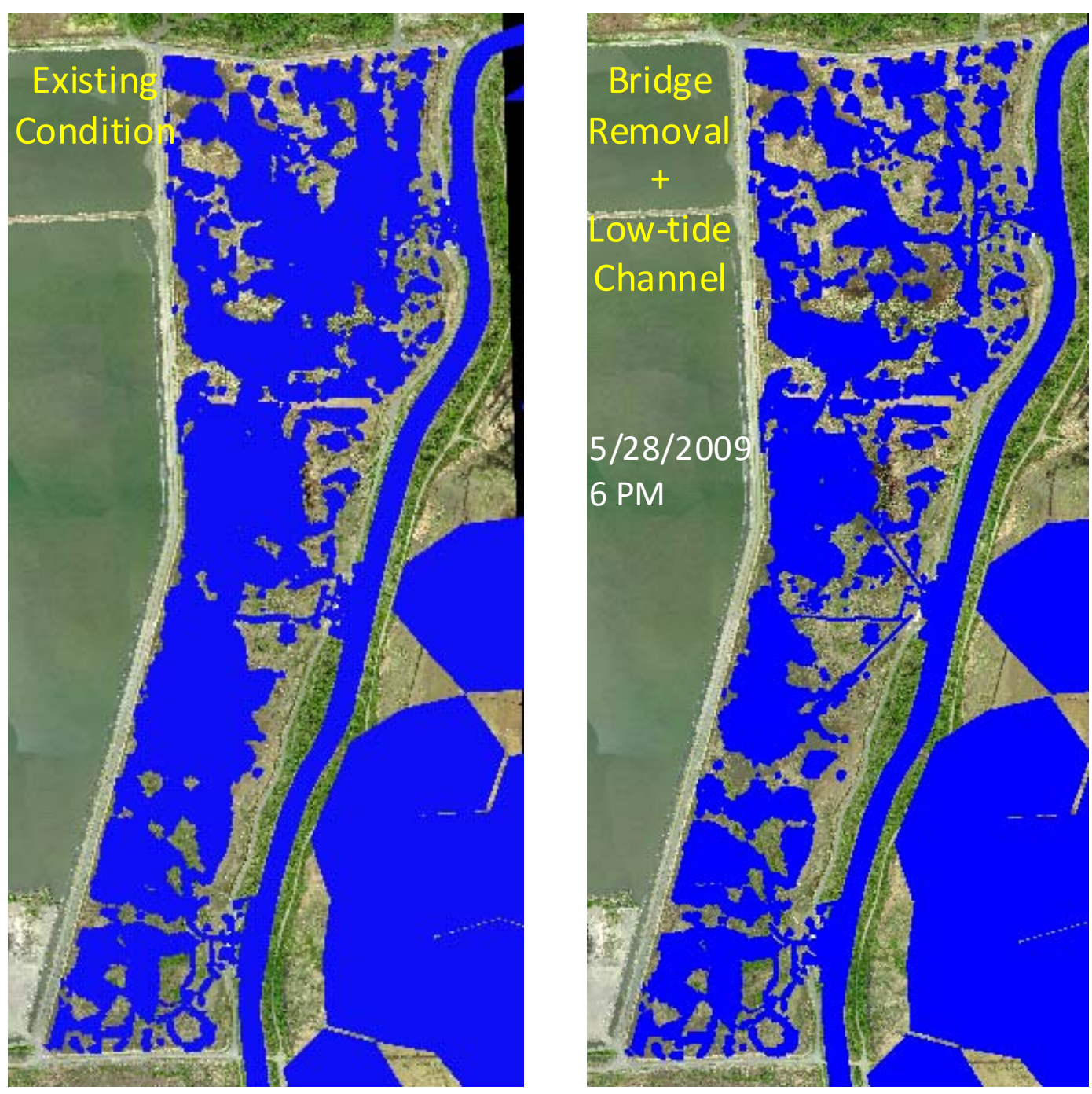

6.5b. Comparison of the Maximum Drainage Areas Under Existing and Bridge Removal+Low Tide Channel Conditions 


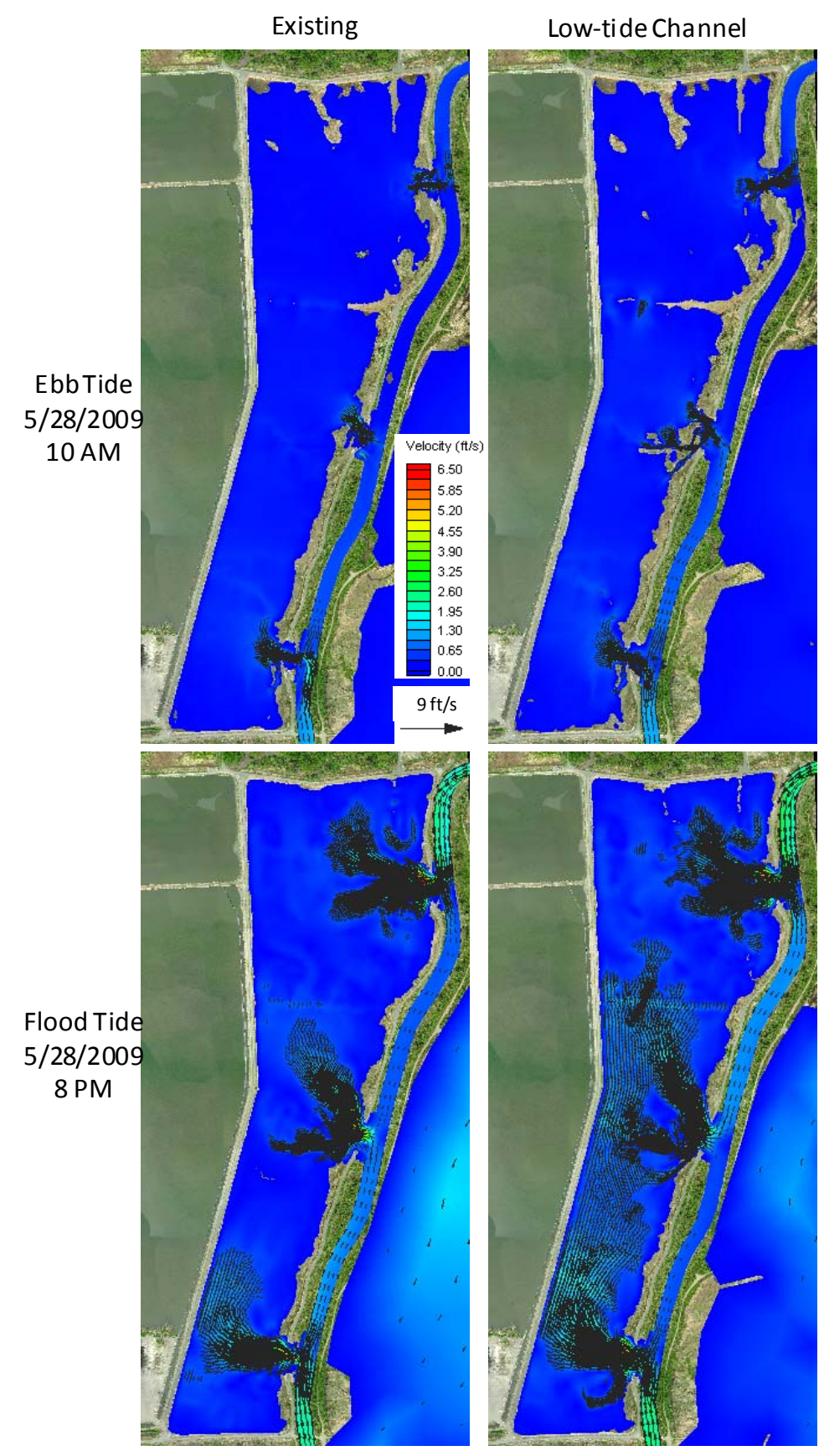

6.6a. Comparisons of Depth-average Velocities at Ebb and Flood Tides Under Existing and Bridge Removal+Low Tide Channel Conditions 


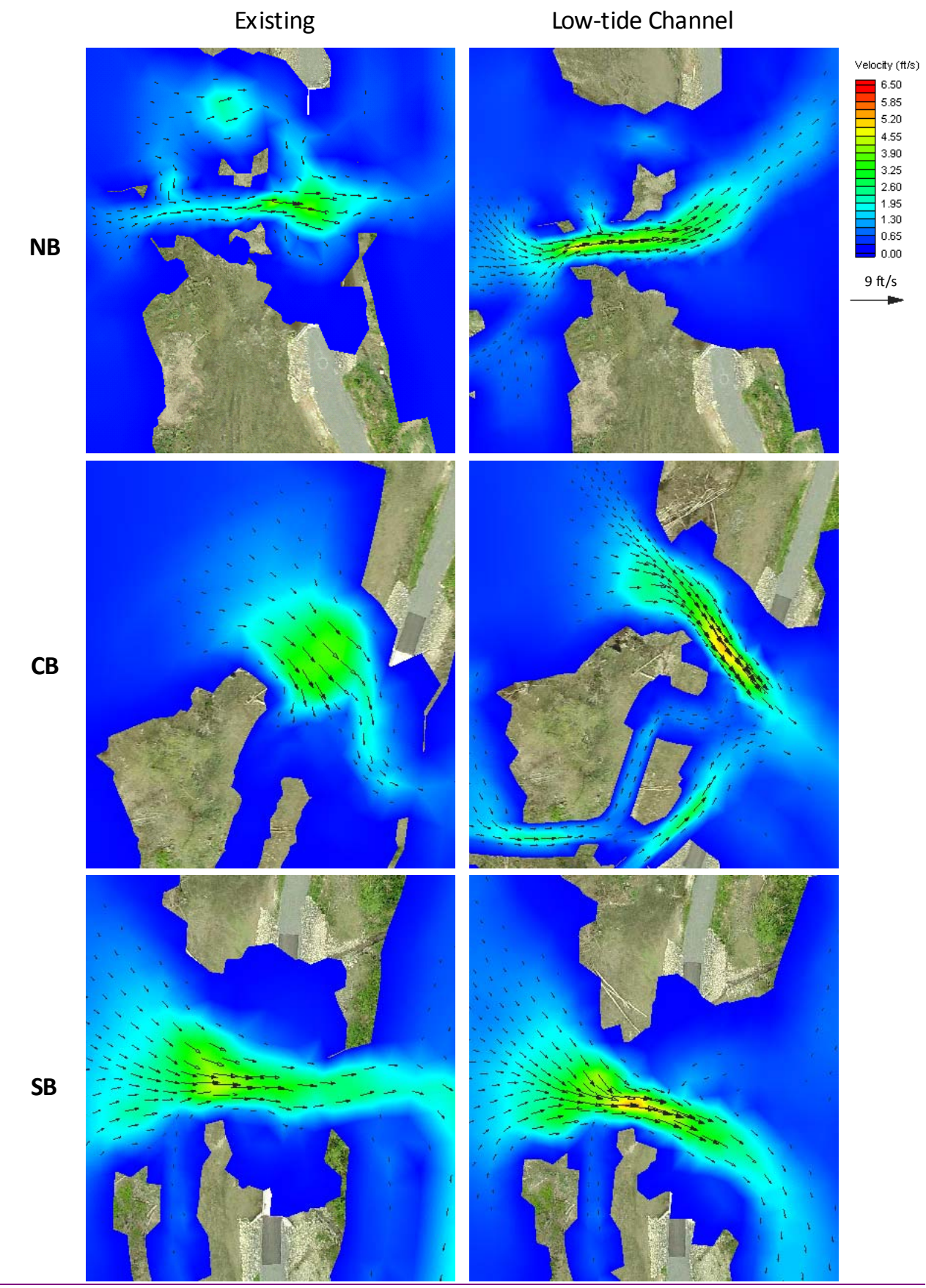

6.6b. Close-up Snapshots of Depth-average Velocities at Ebb Tides near Bridge Locations under Existing and Bridge Removal+Low Tide Channel Conditions 


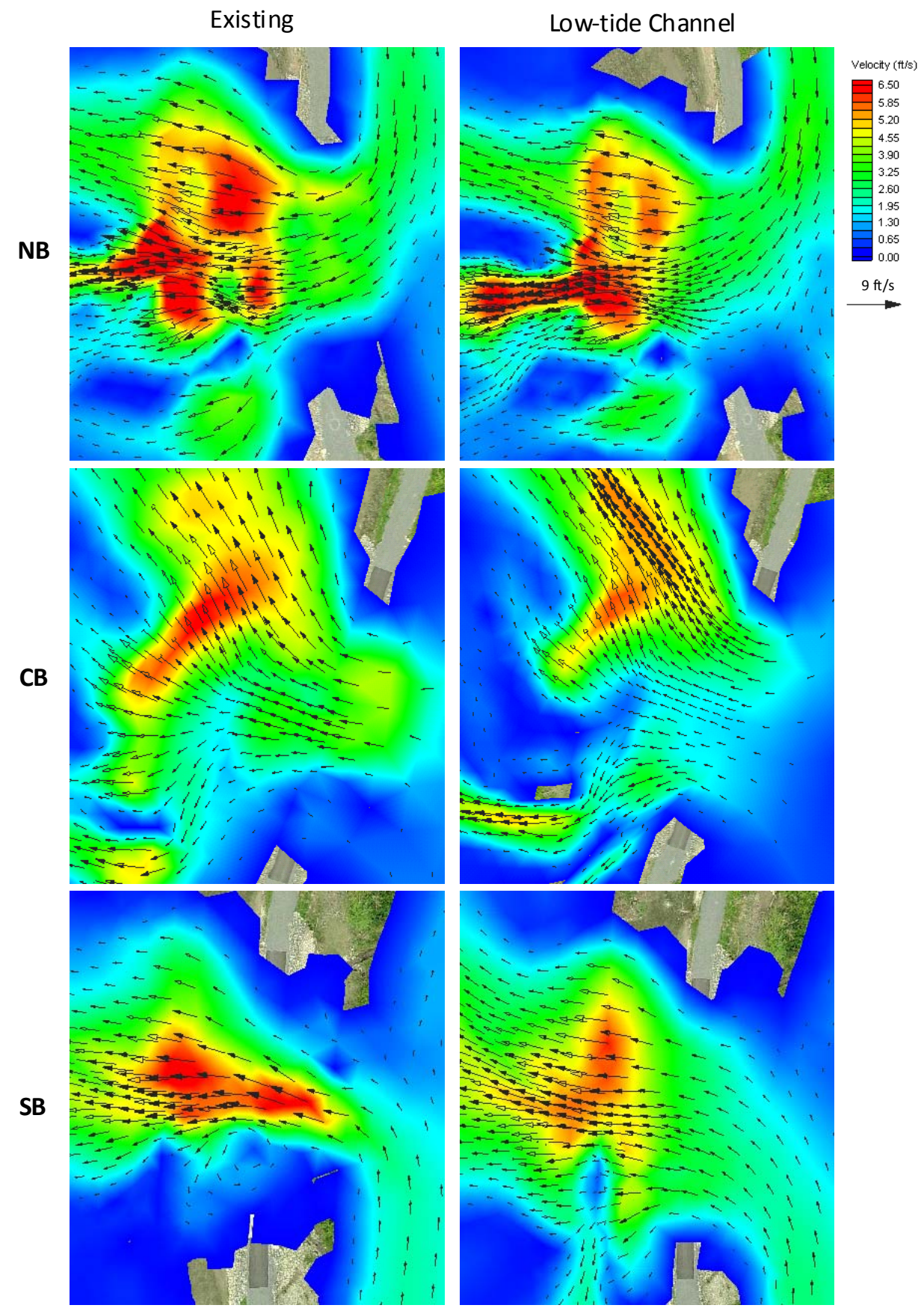

6.6c. Close-up Snapshots of Depth-average Velocities at Flood Tides near Bridge Locations Under Existing and Bridge Removal+Low Tide Channel Conditions 



\subsection{Summary}

In this study, Battelle's 3D Snohomish River estuary model was updated with a fine-grid resolution for the Union Slough project site. The model was validated with observed data collected in the project site and Union Slough for the period of May 27 to June 26, 2009, and applied to evaluate a number of proposed restoration alternatives to improve the drainage function in the project site. The volume of water contained within the site throughout the entire range of tidal conditions was calculated, and error statistics associated with the validation effort are provided. The main findings of this model analysis are summarized below:

- Error statistics for model validation are within an acceptable range (10\%), which is consistent with the standards in the coastal modeling community. The model skill assessment showed that the model has a good capability for predicting water levels and drainage in the project site.

- A methodology was developed for estimating the uncertainty for the predicted drainage area percentage. While the uncertainty of the predicted drainage area percentage varied over time during different tidal phases, the time-average uncertainty for drainage area prediction was small $(3.7 \%)$.

- A simulation of the bridge-removal scenarios using the model indicated that

- Removal of the north bridge was effective in improving the drainage in the northern part of the project site. It resulted in about a 10\% increase in the drainage area during low tides.

- Removal of the central and south bridges showed little improvement in the drainage area, primarily due to disconnected ponding areas and narrow/choking drainage channels to the bridge openings.

- The effects of removing all bridges and removing the north bridge alone on drainage in the project site were almost equivalent.

- A simulation of the low tide channel scenario using the model indicated that

- Low tide channels connecting to the central bridge could further improve the drainage of the project by another $10 \%$ compared to the all-bridges removed scenario.

- Tidal fluctuations in the project site were more in phase with tides in Union Slough under low tide channel conditions.

- Little improvement was observed in the south part of the project site under the low tide channel conditions.

- Based on the model results of all bridges removed and the low tide channel scenario, it appears that construction of additional low tide channels near the south bridge would further improve the drainage area to approximately $70 \%$ during low tides.

The hydrodynamic model of the Snohomish River for the Union Slough Restoration project site can be further improved in the future as more observational data as well as funding become available. Bathymetry data are a key factor in the model configuration. With higher resolution and more accurate bathymetric data, the interior ditches and channels (such as the western channel along the dike) can be better defined in the model. To increase the confidence of the model, it is necessary to validate the model with observed velocity and water surface elevation data at various locations of the project site. To simulate hydrodynamics in an estuarine wetland environment, the presence of vegetation in the form of bottom roughness plays an important role. Incorporating varying bottom roughness into the model based 
on vegetation and geomorphologic information will have the potential to improve the predictions of water levels and velocities inside the project site. 


\subsection{References}

Flater D. 1996. “A Brief Introduction to XTide.” Linux Journal, 32, 51-57.

JCF Jones \& Stokes. 2009. Alternatives Analysis for Adaptive Management of Site Hydraulics and Public Access at the Smith Island/Union Slough Restoration Project. Study Report prepared for Everett Public Works Department, Everett, Washington.

Yang Z and T Khangaonkar. 2007. Hydrodynamic Modeling Study of the Snohomish River Estuary: Snohomish River Estuary Restoration Feasibility Study. PNWD-3864, Pacific Northwest National Laboratory, Richland, Washington. 